\title{
EL DUQUE DE DURAS Y EL FIN DEL MINISTERIO ENSENADA (1752-1754) ${ }^{1}$
}

\author{
por \\ JOSÉ LUIS GÓMEZ URDĀÑEZ \\ Universidad de La Rioja.
}

RESUMEN: A través de la actividad del embajador francés en España, conocida por la amplia correspondencia conservada en Paris, se desgranan algunos de los bechos más importantes de la politica española de mediados del siglo XVIII, entre ellos la exoneración y destierro del marqués de la Ensenada. Se analizan las causas de lo que supuso la mayor crisis polititia en las relaciones bispano-francesas desde la expulsión de la princesa de los Ursinos y se reflexiona sobre el panorama prebélico internacional y la situación de neutralidad española. A la vez como condusión, se apuntan algunas ideas sobre la naturaleza del despotismo español y sobre el papel que desempeña un ministro del Estado administrador como Ensenada y sus dificiles relaciones con la gran nobleza de la domus regia.

PALABRAS CLAVE: Marqués de la Ensenada. Duque de Duras. Diplomacia. Despotismo. Fernando V.

ABSTRACT: The activities of the French ambassador in Spain, recorded in the correspondence kept in Paris, allow us to know some of the most important facts of the Spanish politics at the middle of eighteenth century among them the fall and exile of the marquis of La Ensenada. This paper analyses the causes of the largest political crisis between France and Spain since the expulsion of the princess of Los Ursinos; it also deals with the pre-war international situation and Spanish neutrality. As a conclusion, the author sketches some ideas about the nature of Spanish despotism and about the role of a minister of the administrative state, such as Ensenada, and his difficult relations with the bigher nobility of the domus regia.

KEY WORDS: Marquis of Ensenada. Duque of Duras. Diplomacy. Despotism. Fernando VI.

Uno de los testigos privilegiados y actor secundario del escenario político en que se produce la crisis de julio de 1754 y su efecto más sensible, el arresto

1 Este trabajo se inscribe en el proyecto «El tiempo de Ensenada», subvencionado por la DGICyT, PB- 95-0698, dirigido por José Luis Gómez Urdáñez.

Hipunia, LIX/1, núm. 201 (1999) 217-249 
de Ensenada y de sus más directos colaboradores, fue el duque de Duras, embajador de Francia en Madrid ${ }^{2}$. Enviado en noviembre de 1752, Duras traia la misión indisimulada de estrechar los lazos entre las monarquías de los primos Borbones, un tanto maltrechos, pero, que en realidad, lo estaban sólo en las apariencias: más en asuntos de familia y de protocolo cortesano que en el tenso escenario internacional, que era lo que importaba en Versalles y en Madrid. Si el embajador inglés Benjamin Keene trabajaba a favor de una alianza inglesa, Duras haría lo mismo en beneficio de Francia. Los dos embajadores estaban instruidos, bien que secretamente, sobre lo importante: la debilidad militar de España, el futuro de la América española - por lo que afectaba al progreso y expansión de las colonias francesas e inglesas-y las previsiones sobre el carácter de la proxima guerra, que los más avezados, y entre ellos sobre todo Ensenada, sabían que sería marítima, colonial y además inminente y desde luego inevitable. También sabían quién podía ser valedor de sus intereses en el dramatis personae de la corte madrileña y lo difícil que era su misión: todo el mundo conocía que el testarudo Carvajal había concebido un sistema de neutralidad para España fundado doctrinalmente en las máximas de paz de Saint Pierre y en ideas del humanismo cristiano y que nunca se apartaría de él; también era lugar común que Ensenada no se separaria de Francia aunque fingiera seguir el sistema carvajalista y que sus planes en la Marina, tras los primeros éxitos, empezaban a ser inquietantes ${ }^{3}$ :

El duque de Duras estuvo siempre «de oficio» cerca de Carvajal, a quien detestaba en privado pero respetaba porque, como todo el mundo, le sabía «íncapable de revenir de son opinion', pero más de Ensenada, a cuyos encantos sucumbió pronto. Nada le hacía sentirse más orgulloso ante los ministros Saint Severin, Saint Contest y Rouillé y ante el mariscal Noailles, su mejor amigo, como el poder trasmitir las confidencias del marqués, agigantadas las más de las veces. Cultivar la deliciosa conversación del estereotipado profrancés Ensenada acabó por ser su principal dedicación. Fue por ello un elemento más de la conjura de julio del 54, aunque pasivo, y el que más agitó el panotama internacional en los meses que siguieron a la caida de Ensenada, tanto por su fervor ensenadista como por sus desmedidas maniobras para evitar una guerra contra Francia, que creía inmediata, sin haber podido conseguir involucrar a España. En ello se empleó a fondo, sufrió situaciones que él mismo calificó de terribles y al fin hubo de ser retirado de Madrid sin honores. Desde principios

2 Buena parte de la documentación utilizada más recientemente procede de AAEP (Archives du Ministère des Affaires Etrangères, Paris). Correspondance politique. Espagne. En adelante la correspondencia de Duras con Noailles (N), Saint Contest (SC) y Rouillé (R), procedente de este archivo, sólo se citará por los tomos en que se encuentra encuadernada y por las inicales del destinatario seguida del lugar y la feclıa. También se ha utilizado la serie Memoires et documents y los volúmenes de la conocida colección Recueils des instructions...

3 Sobre el particular no hay más remedio que remitir a mi E/ proyecto reformista de Ensentada, Lleida, Milesio, 1996. En él hay una introducción de carácter historiográfico crítico y una bibliografia que no citaré aquí con la amplitud que merecen los temas tratados.

Hihtonia, L.IX/1, núm. 201 (1999) 217-249 
de 1754, a poco más de un año de llegar a Madrid, logró saber que en Versalles se hablaba muy mal de su labor, incluso que ya tenía sustituto: supo que ya se hablaba de Ossum. Muerto Saint Contest, poco después de la caída de Ensenada, y nombrado Rouillé ministro de asuntos exteriores, que no le estimaba, su reputación estaba sentenciada. Hay que añadir que el ministro de asuntos exteriores que le tocó en suerte, François Dominique Barberie, marqués de Saint Contest, fue uno de los ministros más incapaces que ha tenido Francia en el XVIII ${ }^{4}$.

\section{EL EMBAJADOR DURAS Y LA CORTE DE MADRID}

Enmanuele Felicité Durfort, duque de Duras, llegó a Madrid el 27 de noviembre de 1752. Sucedía a Vaulgrenant, un embajador mediocte que no había podido impedir la firma de un tratado comercial hispano-inglés ni había conseguido reforzar oficialmente la alianza hispano-francesa. Al final se había hecho impopular entre los ministros, aunque menos que Vaureal, el obispo de Rennes, su antecesor, que había llegado casi a la ruptura con Ensenada y con personajes importantes del entorno cortesano. Resultaba evidente que en Versalles no podían estar muy satisfechos de sus últimos embajadores en Madrid. De hecho, si exceptuamos al duque de Noailles, mariscal de Francia, que llegó a ministro de Estado tras un paso fugaz por la embajada madrileña, ninguno hizo luego carrera rápida como se esperaba una vez cumplido el sejour en la incómoda corte española, que, no hay que insistir, eta la más importante en las relaciones internacionales francesas, pero también la más dificil desde que Fernando VI ciñó la corona:

«Il ne faut pas nous y tromper — confesaba Noailles-, 46 ans du regne de Philipe $V$ nous ont gagné fort peu de coeurs espagnols; nous n'aurons pas a combatre les emportements d'une reine italienne, mais une opposition constante dans toute cette nations ${ }^{5}$.

Los diplomáticos franceses tomaban Madrid como un mérito importante para su cursus bonorum, pero conocían bien las dificultades que planteaba la nueva situación política creada por Fernando VI y lo poco brillante que resultaba su trabajo en Madrid: España seguía más neutral que nunca y, sobre todo después del asunto del rechazo de Luis XV de la boda de la infanta, los monarcas

4 Las críticas son unánimes. Duras se atreve a mostrar ante Rouillé los defectos del ministro aún estando próxima la fecha de su muerte. Con todo, Samoyault, que refiere la sorpresa de Choiseul cuando supo que en más de tres meses Saint Contest no había dado acuse de recibo a las cartas de Duras, no tiene en cuenta que el ministro había estado en cama y que no saldria de ella. Cfr. AAEP, T. 515, R, 15 de agosto de 1754, y SAMOYAuLT, J.P., Les bureatx du secrétariat d'état des Affaires Etrangères sous Louir XV, Paris, 1971, espec. pp. 28 y 53.

5 Cit. en DanVILA, A., Estudios españoles del siglo XVIII. Fernado VI y $D^{a}$. Bärbara de Braganza, Madrid, 1905, p. 240. Sobre la francofobia popular, cft. EG1Do, T., Opinión puiblicay oposiction al poder en la España del siglo XVIII (1739-1759), Valladolid, 1971.

Ḩăpaniti, LJX/1, núm, 201 (1999) 217-249) 
se habín alejado sentimentalmente de sus primos franceses; Fernando VI había llegado a creerse su destino de monarca español, trabajosamente fabricado por Ensenada y Carvajal ' nos grandes como el propio Carvajal, que escribia lindezas como las siguientes:

(Los franceses) «tienen para nosotros una enemistad irreconciliable que nos asesinarán hasta el último exterminio siempre que puedan» (1745).

«Todo lo demás (de Francia) es repugnante, empezando por el carácter de los individuos" $(1753)^{\text {? }}$.

Versalles tuvo muy en cuenta la situación al elegir un nuevo embajador. Antetodo, debía ser un buen cortesano y además un noble con título distinguido (Vaulgrenant sólo era conde de Villers-La Faye),

«ll seroit a desirer que ce fut une personne de nom et distinction, que ce fut un homme titré pour n'etre point tenté par l'apas de la grandesse et pour avoir d'ailleurs plus de consideration et phus de facilités pour les entrées et l'acces à la couns? ${ }^{8}$.

Los problemas de protocolo entre las dos cortes y las diferencias de tratamiento que recibían los nobles españoles en París -esto venía de los tiempos de Luis XIV, como es sabido- con respecto a los que se tributaban en España a cualquier répresentante de la noblesse de robe francesa excitaban los celos y el rechazo de los grandes españoles ${ }^{9}$. Había que cuidar ese extremo. Eta frecuentemente interpretado como un rasgo de sobetbia y altanería tópicamente francesas, y se sabía que estos extremos eran insoportables para los españoles, como Duras tendría ocasión de comprobar ${ }^{10}$, de forma que incluso en la teatralidad había que rebajar el tono.

6 Ias representaciones de Ensenada están plagadas de llamadas a restaurar la España de los buenos tiempos del Imperio. La mejor muestra material de hasta donde llegó la (progtamacións de la españolización de la corte y del monarca es el proyecto iconográfico que se le encargó al P. Sarmiento para la decoración del Palacio Real. Sobre ello hay documentación abundante, cfe por ejemplo AHN, Estado, leg. 2.604. Véase también PLAZA SANIIAGo, F.J de la, Invertigaciónes sobre el Palacio Real Nueto de Madrid, Vallado Ed, 1975. Sobre la uespañolizacióm», véase Gómez Molleda, MD, «El pensamiento de Don José Carvajal y Lancáster en la política intemacional española del siglo XVIII. Utopía y realismo de una polítican. Arbor, (febrero 1954) y "Viejo y nuevo estilo político de la Corte de Femando Vls. Eidos, 6 (1957).

7 Carvajal y Lancáster J., Testamento..., 1745, y Mis pensamientas..., 1745, manuscritos, BN, mss., 10.687. En ocho años no había cambiado. Era así.

8 AAEP, Memoires et documents..., T. 197, f. 4 y ss.

9 Un pliego anónimo titulado Diphomaticus et etiquete, sobre el que no me detengo, es un buen ejernplo de las críticas que menecía a los grandes la diferencia de trato entre ellos y los pares de Francia, un tema que dio bastante que hablar en la corte de Fernando VI. Las comparaciones de las diferentes etiquetas incluyen la del Vaticano, en donde el papa no recibe a los grandes españoles y no pasa nada; en realidad, se trata de una rechifla, de las habituales en la época, sobre las pretensiones de honores de la alta nobleza. Se cita a Huéscar como uno de los que no soportan el trato. Cfr. AHN. Estado, leg. 2499.

30 Los embajadores se referian pocas veces al pueblo y las más sólo para ratificar tópicos. Duras, en una de estas ocasiones decía que los españoles eran altaneros (hauts), desconfiados, pero sensibles a la amistad y a la consideración. AAEP, T. 512, N., Aranjuez, 23 de mayo de 1753.

Hiquania, LIX/1, núm. 20t (1999) 217-24') 
"On n'entend pas par là que notre embassadeur donne dans un faste et une magnificence ridicules, mais que sa maison ait un air d'abondance, de dignité et de décence».

Explícitamente, se intentaba rectificar los errores del anterior embajador: "On sfait à cet égard ce qu'on a reprocbé à $M$. de Vaulgrenant». Con todo, no había que exagerar más que en la apariencia, pues

«La maison d'un embassadeur de France à Madrid doit etre en quelque sorte le rendez vous général de tout ce qu'il y a de plus grand et de meilleur tant dans la nation que parmi les ministres étrangers».

Incluso se solicitaba del nuevo embajador que tuviera maneras más uversallescas» en ciertas demostraciones públicas:

«Il seroit à desirer qu'il fut en état de faire quelques actes de générosité envers les pauvres et les malheureuxy.

Debía dar también limosnas «par le canal des curés». Eta lo que sabian que hacía el embajador inglés Keene - nada que decir de la diferencia de credo-y en Versalles se creía que éste era

«e moyen le plus sur de gagner l'estime et l'afection d'une nation qui a naturallement de l'inclination pour les actions généreusesn.

En la Europa de los salones, las tertulias y los chichisveos, contaba también y mucho la esposa del embajador — sin duda, debía ser casado-, a la que se le solicitaba ser capaz de lograr el acceso a la reina y mantener reuniones en su casa con la gente más importante. No hacía falta advertirlo: los embajadores se apresuran a contar a sus corresponsales estos logros como propios.

Peto al matgen de estas reglas diplomáticas y cortesanas un tanto tópicas, lo importante era el núcleo «políticon de la corte: los ministros. Y entre los ministros, para Versalles, sólo contaban dos: Carvajal y Ensenada. Con ellos el embajador debía extremar el celo y sobre todo cuidar sus maneras para no mostrar preferencia por uno u otro, lo que podría acarrearle graves problemas. Lo opuesto del carácter de cada uno de ellos y las diferencias de sus concepciones políticas habian pasado a engrosar los estereotipos sobre uno y otro y sobre sus tormentosas relaciones. Carvajal, insobornable, tenaz y opuesto a profundizar en la alianza con Francia para no presionar a Inglaterra y tomper la neutralidad; Ensenada, cínico, todo apariencia, favorable a Francia, pero dispuesto a una alianza cuando estuviera en condiciones militares - su gran baza, la Marina - para no sufrir nuevas humillaciones por parte de los franceses. Con estas primeras uinstrucciones» un tanto tópicas y con las noticias que obtendría de su amigo Noailles, buen conocedor de la política española y del marqués de la Ensenada y su entorno cortesano -los Farinelli, la de La Torrecilla, la de Torrecuso, la de Salas, Losada y la Farnesio-, venía Duras a Madrid. 
$\mathrm{Al}$ día siguiente de llegar fue recibido en palacio. Los reyes le dirigieron la palabra, Ensenada le mostró estar contento por su nombramiento y Carvajal, contra pronóstico -el embajador se sorprendió-, hasta sonrió. Con todo, Duras tuvo la impresión de que Ensenada le consideraba «simple en sut maneras» y hasta "incapable de finesses et de tromperies», lo que conociendo la reputación del marqués no debió ser para Duras un halago. Para redondear el éxito, ese mismo día recibió en su casa una «deputation» de jesuitas con el confesor, el P. Rávago, a la cabeza. No podía ser más feliz y se apresuró a confesarlo a su amigo y protector Noailles ese mismo día ${ }^{11}$.

El éxito, sin embargo, no iba a acompañar la embajada de Duras. Con sólo observar el grado de cumplimiento de las instrucciones que recibió luego analizaremos el objetivo principal, el reforzamiento de la alianza, y el acto culminante, la caída de Ensenada, que se convirtió en su gran fracaso-, podemos afirmar que incluso en los aspectos meramente cortesanos su actuación fue poco brillante. Consiguió que su mujer y sus hijos tuvieran introducción en la corte, pero no hasta el punto de lograr confidencias importantes como las que podía tener, por ejemplo, el embajador portugués y, desde luego, en su estimación, quedó siempre lejos de la que se reputaba a Keene, su rival.

Duras no logró nunca una buena posición ante los reyes. Era muy dífícil. Isabel Farnesio y los restos de la corte afrancesada de Felipe V recluidos en San Ildefonso provocaban el desasosiego de Fernando VI que sabía de sus relacionesparalelas con la familia francesa. Pero contaban también las "peculiaridades» de la real pareja. Si no se disfrutaba de ciertos actos rutinarios, como le ocurría al embajador, la aproximación a los monarcas era difícil. Por ejemplo, Duras no soportaba la ópera, lo que en una corte musical como fue la de Bárbara suponía un suplicio, como él mismo decía, pues la ópera, -el (pasto ordinario» como la llamaba Carvajal, que también la aborrecía -, era diaria por la tarde y además "desgraciadamente» ...obligatoria ${ }^{12}$. Farinelli y sus músicos, con el beneplácito de Bárbara, habían desterrado de la corte cualquier música que no fuera italiana, incluída la francesa, y la ópera italiana del momento era realmente soporífera. Bárbara, que solía acompañar a los músicos y cantantes tocando el clave en los ensayos, y a Farinelli formando duo, en privado y a veces en público, empleaba buena parte del día en su afición. El rey la contemplaba feliz y hacía que sus ministros le trajeran instrumentos y partituras de Italia - de esto se encargaba personalmente Ensenada - y la halagaba constantemente presenciando las sesiones.

11 AAEP, T. 512, N., Madrid, 28 de noviembre de 1752.

12 Tras el restablecimiento de la reina, de suplice des operas recommencera. C'est un des grands fleaux de cette cour et malhereusement on est obligé de n'en pas manquer unen. A veces, se irrita por las costumbres de la corte que retrasan sus planes: «C'etoit hier jour de chapelle le matin et d'opera pour le soir, en sorte que je n'ai pu joindre $M$. de Carvajal pour raisonner avec lui sur les matieres qui contient votre depechen. AAEP, T. 515, SC, Madrid, 6 de febrero de 1754 y 7 de enero de 1754 .

Hipania, L.IX/1, núm. 201 (1999) 217-249 
Al rey le quedaba tiempo, no obstante, para cazar. No llegó ni con mucho a los extremos de su hermano Carlos, indiscutiblemente un cazador compulsivo ${ }^{13}$, pero fue suficiente para que Duras se sorprendiera de su apasionamiento. El embajador observó ya durante su primer invierno que, a pesar del frío madrileño, el rey no dejaba de ir a la caza ni un sólo dia ${ }^{14}$. Todavía presenciaria durante la última primavera de Ensenada en Aranjuez la célebre escuadra del Tajo, cuando los barcos a escala y las falúas, repletos de cortesanos disfrazados - Ensenada, de almirante--, hacían constantes paradas para que el rey matara algunos animales desde la orilla, mientras la reina y Fatinelli cantaban ${ }^{15}$. Y es que mantener contentos y distraidos a los reyes - sobre todo a Fernando-, alejados de las tensiones políticas, era la gtan obra a la que se entregaron Ensenada y el P. Rávago.

"Esta es toda la dificultad: hallar en que divierta muchas horas honestamente, porque el reloj no se pare y todo lo demás se descuaderne». ${ }^{16}$

Por eso Duras tenía grandes dificultades para acercarse a la feliz pareja, más para hacerle llegar alguna representación que no fuera un halago o unas palabras protocolarias. Era, sin embargo, un hombre muy testarudo y siempre insistió en llevar las relaciones internacionales al campo familiar. Cuando vio en peligro la alianza francoespañola tràs la caída de Ensenada todavía seguia con la idea de que si los reyes, español y francés, se escribieran personalmente se evitarian malentendidos. Hubo de recibir instrucciones de Versalles sobre la prudencia con que debía acometer el asunto. Fernando VI había sido convencido de que no se volvería a doblegar ante Francia y hacía exbibición de su gobierno «español», de forma que, a excepción de las cartas familiares - bautizos, cumpleaños, etc.-, rechazaba cualquier otra sobre asuntos políticos que viniera de Francia. En Versalles era asunto conocido. El mismo embajador había podido comprobar lo que tanto temían Rávago y Ensenada, que al rey le diera la melancolia al conocer asuntos graves, sobre todo las temibles injerencias ex-

13 La correspondencia entre los dos hermanos suele comenzar con las noticias sobre la caza. Tomo una carta de Carlos al azar. «Hermano de mi vida y de mi corazón (...) yo continúo a divertirme muy bien, pues en esta semana he muerto 30 chochas, 8 agachadizas y 24 ánades y entre todos, incluso esto, se han muerto 3 zorras, 5 liebres, 91 chochas, 15 agachadizas y 77 ánades, y espero en Dios que tu continúes a divertirte tanto como yo deseo, y el dia 7 del que viene nos iremos a Bovino donde espero nos divertiremos bien pues me aseguran que hay muchísima cazay. AGS. Estado, leg. 6080. Carlos de Nápoles a Fernando VI, 23 de enero de 1753 .

14 AAEP, T. 512, N., Madrid, 12 de diciembre de 1752.

15 Sobre estas «finvolidades», v. GaRCí Rrves, A., Fernando VIy D. Bárbara de Braganza. Apuntes sobre su reinado (1746-1759). Madrid, 1917.

16 Rávago a Portocarrero, Madrid, 31 de marzo de 1751. En Percyra C. y Pérez Busta. MANTE, C., Correspondencia reservada e inédita del P. Francisio de Rávago, confesor de Fernando VT. Madrid, s.f., p. 249. Véase sobre Rávago el excelente estudio ALCARAZ GÓmEZ, J.F,, Jesuitas y reformismo. El padre Francisco de Rávago (1747-1755), Valencia, 1995. 
tranjeras, y se trabaran todas las claves del gobierno, pues Fernando tenía "rarezas" parecidas a las de su padre:

(Fernando VI) «tient beaucoups de son pere et a quelque fois la fantaissie de ne vouloir pas se levers ${ }^{17}$.

Cuando Duras escribía esto hacia dos días que el rey no se levantaba de la cama a pesar de las súplicas de la reina y de la intervención del P. Rávago. Al fin salió de su cámara con los ojos enrojecidos, pudo saber Duras, que atribuía el asunto a un disgusto causado por Ensenada. Eran tan habituales ya en los años 53 y 54 que el embajador llegó a estar convencido de que el rey odiaba a Ensenada y sólo le mantenía por la intercesión de la reina y de Rávago. La situación de Ensenada, cada vez más peligrosa, le disgustaba sobremanera. Le apreciaba personalmente y le necesitaba políticamente, porque, a pesar de las instrucciones recibidas para que no se inclinata hacia ninguno de los dos grandes ministros, Carvajal le resultaba insoportable y sospechoso de no mover un dedo a su favor "Tetü, ignorant, soupconneux», su política es no variar nada. Duras, completamente ganado por el marqués, el único hombre en quien puede apoyarse, acabará exclamando: "Quelle difference de celui ci (Carvajal) a mons. Le marquis de la Ensenadas. Y aún escribirá repetidamente que Carvajal estaba completamente ganado por los ingleses, un juicio no sólo erróneo sino además imprudente ${ }^{18}$.

Con el tiempo demostrará que la personalidad de Ensenada le subyugaba completamente, aunque recibía constantes instrucciones de Francia de que lo que interesaba era la armonía entre los dos. Y en cuanto a Carvajal, si él transmitía impresiones negativas sobre el ministro testarudo e ignorante, éste, al que Duras verdaderamente llegaba a abrumar con su pesadez, le describía en términos parecidos (sin llegat al insulto, inusual en Carvajal):

«El embajador de Francia desde que llegó me ha estado atormentando con proyectos ya de alianza ya de comercio, y en fin, su asunto continuo es volver a pone $\mathrm{r}$ a este reino a las órdenes y dependencia del suyo y el mío disipar semejante plagas. (...) Que se acordase (el embajador) de lo mucho que le había dicho para que su amo no hiciese tal demanda, pues lejos de eso ha publicado que lo ha logrado todo y se muestra el embajador muy contentom. ${ }^{19}$.

Duras tampoco gozó del agrado de las gentes. Era conocida la antipatía popular contra los franceses y a la caída de Ensenada rebrotaría ${ }^{20}$. Era sin duda excitada por una parte de la élite, como suele ocurrir con las pasiones xenófo-

17 AAEP, T. 512, N., Aranjuez, 23 de mayo de 1753.

I8 Entre otras cartas, en las que se repiten los mismos juicios machaconamente, AAEP, T 512, N., Madrid, Aranjuez, 17 de junio de 1753. Poco antes, ha llegado a decir de Carvajal que era un ignorante falto de luces, envidioso de Ensenada, aunque eno puede hacerle ningún dañon. Ibid., Aranjuez, 15 de mayo de 1753. Con todo, le veremos cambiar de opinión tantas veces como varien los rumores de la corte.

19 AHN, Estado, leg. 4273. Carvajal a Wall, 9 de enero de 1754.

20 Egido, T., Opinión pública..

Hiipania, LIX/1, núm. 201 (1999) 217-249 
bas, y la pudo ver y sentir cotidianamente. Fue testigo de los tópicos sobre la inmoralidad de los franceses que corrían por la corte, pero no sabía cómo responder. Durante su primera estación en Aranjuez le decía a Noailles:

«Je ne puis vous disimuler que les affaires du parlement et du clergé font ici un effect terrible et que le roi d'Espagne en gemit tous les jours. Les uns representent la France comme le sejour de l'atheisme, d'autres disent que l'authorité royalle est totalment perdue et que l'anarchie regne dans touts les ordres, on ne sait que respondres ${ }^{21}$.

Tuvo que atender a las quejas sobre el trato que sufrían algunos cónsules y comerciantes franceses en los puertos, que llegó a pensar tenían menos estimación incluso que los ingleses, y a episodios de mera piratería que solia exagerar ${ }^{22}$. Sus sospechas sobre un giro español hacia Inglaterra eran constantes y las alimentaba frecuentemente con indicios ante Carvajal que sabía que no respodían a la verdad ${ }^{23}$; escudriñaba el comportamiento de Keene y se dejaba llevar hasta por el semblante que tenía el embajador; si era bueno, se temía lo peor. Por el contratio, seguía con alborozo los fracasos de su rival y los comunicaba como un éxito de su misión. A veces, sin embargo, se dejaba engañat, como cuando en los días anteriores a la caída de Ensenada, el gran éxito de Keene, éste, según Duras, mostraba un mal semblante y había dicho que quería abandonar Madrid.

Intentó el soborno para algunos asuntos, como era habitual entre los diplomáticos, pero sin grandes éxitos - desde luego, menos que Keene-y demostrando cierta imprudencia, que fue reconvenida a veces desde Versalles. En medio de la tensión desatada por la política de Ensenada en las Antillas, ya en 1754, un confidente que se le presentó como «commis» del ministerio de Exteriores, le probó a cambio de cien pistolas de oro que Carvajal había conseguido la clave de la cifra que él empleaba para escribir a Noailles. Duras le ofreció más dinero si le traía cartas de Masones y Wall, pero no creo que lograra ni una; al menos no volvió a mencionar el asunto ni envió información con esa procedencia. Si consiguió, poco después, saber que Carvajal había interceptado y descifrado cartas de Keene, y que su contenido había encolerizado al ministro. El embajador llegó a conocer una carta en la que Carvajal era ferozmente insultado por el embajador inglés — - iil etoit sans religion, sans probité et sans aucuns prin-

21 AAEP., T. 512, N., Madrid, Aranjuez, 21 de mayo de 1753.

22 A juzgar por las "presas" de corsarios «españoles», algunas francesas, la inquietud de Duras estaba justificada. V. STapes ls Johnson, V., Los corsarios de Santo Domingo, 1718-1779: un estudio socio-económico, Lleida, 1992, especialmente los cuadros de pp. 75 y ss.

23 Masones de Lima, embajador en París, llegó a desesperarse por lo que juzgaba ugenio puerilmente asustadizo dal duque de Duras» y llegó a hablarle al ministro Rouillé de sus imprudencias. AGS, Estado, leg. 4522. Masones a Wall, 18 de noviembre de 1754. Sobre usus torpezas y sus imprudencias», cfr. OzANAM, D., "La política exterior de España en tiempo de Felipe V y Fernado VIn. Historia de España de Ramón Menéndę Pidal, t. XXIX, vol. I. Madrid, 1985, pp. 443699 , especialmente p. 682 . 
cipes) $>$ - y, eufórico por la desgracia de su rival Keene, pintaba un Carvajal profrancés: "qu'il paroissoit abojourdbui livré a la France et qu'll n'y avoit rien a esperer pour les angloiss ${ }^{24}$. Era lo que le decía Ensenada: si Inglaterra llegara a la guerra, Carvajal no tendría otro remedio que acercarse a Francia. Puro cálculo de fuerzas.

Durante su primera estancia en Aranjuez, intentó sonsacar información a un prete y un jurisconsulto que acompañaban a Carvajal en sus paseos y sobornó con una cajita de oro a un tal Rodolfi, un confidente spresque governeur de $F a$ rinellin, para que mediara ante su patrón, y por tanto ante Bátbara, a favor del $\mathrm{P}$. Martínez, un jesuita partidiario de Francia, candidato a la sucesión del confesionario de la reina. El titular, una creatura del P. Lefebvre, el antecesor afrancesado de Rávago, estaba en el lecho de muerte (se decía) y, según decía Duras, Ensenada «está en ello y quiere a este sucesom. Llegó a solicitar un envío de 20.000 francos para pagar al confidente, pero Versalles no debió acceder ${ }^{25}$.

Conocedor de este mundo de intriga y soborno, Duras no se aplicó a sí mismo las necesarias medidas de prudencia ${ }^{26}$. No cambió la cifra, como hacía Ensenada con frecuencia, y se permitía juicios en cartas sin cifrar que si hubieran sido descubiertos le hubieran acarteado la más absoluta desgracia. Por ejemplo, al informar sobre la enfermedad de la reina durante el sejour de Aranjuez de 1753, se atrevió a escribir que stout le monde sera enchanté de sa morts. En sucesivas cartas iba notificando con detalle la evolución de la regia enferma a la vez que preparaba la estrategia de un futuro matrimonio de Fernando VI, evidentemente con una princesa francesa. Daba por muerta a Bárbara con diagnósticos tan extraños como el siguiente:

«elle perira quand elle sera arrivée au temps critique des fernmes, ce qui ne peut etre elloignée ayant quarante cuatre ans».

Y aún se explayaba en mostrar sus conocimientos diciendo que las mujeres de los países cálidos, y especialmente las portuguesas, suelen motir pronto y además, de repente, sin médico ni confesor. Al final, la reina se repuso en unos días. Era normal que todos los años pasara algunos dias malos en Aranjuez. Su glotonería le acarreaba constantes accidentes ${ }^{27}$.

En los asuntos decisivos de la política internacional, sobre todo en lo concerniente a la política del marqués de la Ensenada, Duras pudo ser realmente

24 AAEP, T. 515, SC., Madrid, 6 de febrero de 1754. Desde Versalles no se explican la torpeza de Keene, siendo tan prudente. Cfr respuesta de Saint Contest, ibid.

25 AAEP., T. 512, N., Aranjuez, 17 de junio, 16 y 21 de mayo de 1753 . Ya se verá luego que sus pronósticos en materia de enfermedades no solían ser acertados: el confesor murió en agosto del año siguiente.

26 La experiencia diplomática en esto es tal que en Paris el embajador inglés Abermale se extrañó ante Masones de Lima, dias después de la caída de Ensenada, de que no hubieran desvalijado al correo que envió Duras en persona desde Madrid. V. GómEZ URDíñez, J.L., El proyecto reformista..., p. 152.

27 Al año siguiente, por ejemplo, volvió a estar muy enferma, con un grano en el ojo, catarros y fiebre. Ya era habitual que no durmiera por las noches, como le pasaba también al rey y le habia ocurrido a Felipe V. De nuevo, Duras no acertó.

Hijpanta, LIX/1, núm. 201 (1999) 217-249) 
indiscreto, como apreciarían Masones de Lima luego y el propio ministro Rouillé. Probablemente no es Ensenada el que hablaba mucho como dice J. Lynch ${ }^{28}$, sino algunos de los que le rodeaban, para los que el mayor triunfo eta exhibir has confidencias del marqués, frecuentemente para mostrar su grado de estimación. Duras fue uno de ellos. Es bastante probable que los primeros rumores sobre las pretendidas cartas que envió Ensenada a América con órdenes ofensivas contra los ingleses, que es lo que se le haría creer a la real pareja el 20 de julio de 1754 —el sestábamos en guerra sin saberloy que dijo el rey-, salieran del círculo de Duras y de sus corresponsales en Versalles y llegaran al astuto Keene, que debió pagar por estas noticias; incluso, es probable que tales órdenes no fueran más que un golpe de efecto del marqués, uno más, para airear la superioridad de su marina y hacerse temer de Inglaterra, lo que hacía ya desde 1752 al conocer los asentamientos ingleses en Honduras ${ }^{29}$. Es probable que las ótdenes no fueran diferentes a las habituales que se enviaban a los gobernadores cuando se recrudecía la piratería inglesa, como estaba pasando en 1753-54 con el palo de Campeche. Como hemos apuntado en otro lugar, ni Keene tenía las cartas ni Wall las encontró ${ }^{30}$. Fue la carta del propio embajador en Londres, Abreu, la que tatificó las sospechas de la preparación de un ataque, como él mismo escribió luego, consciente de que se había utilizado su carta en la deposición del marqués:

«Luego que el rey se enteró de mi carta del 9 (la que llegó el 18 y le mostraron el 19) pensó Su Majestad se asegurase al St. marqués de la Ensenadas ${ }^{31}$.

28 «Era un hombre que pensaba demasiado poco y hablaba en exceso? ¿Eran sus proyectos realistas, sus informes y memoriales proyectos de acción? 20 más bien eran ejercicios teóricos más allá de las posibilidades del Estado español? Existe la sospecha de que Ensenada prometía más de lo que conseguias. Lynch, J. El siglo XVIII..., p. 168.

29 Por ejemplo, había escrito a Wall para que trasmitiera al gobierno inglés que estaba preparado y no temía la guerra: una balandronada, pues siempre insistía en que faltaban dos o tres años para tener preparada la marina. AAEP., T. 512, N., Aranjuez, 27 de junio de 1753. Véase también infra. En cualquer caso, Wall, seguidor del pacifismo carvajalista y opuesto a la guerra contra Inglaterra, no presionaba a los ingleses ni les transmitía amenazas. Al contratio, procuraba evitar lo que temía tanto como su "patróns. Vid. El proyecto reformista..., p. 151 y ss.

30 La célebre carta de Keene, transcrita en casi su totalidad por Coxe, que ha sido la fuente casi única de la que salió la explicación más frecuente: «Por forturna - dice Keene- llegó en la mañana del 19 el correo portador de vuestros pliegos del 8 , lo que dio nuevo vigor a las operaciones ya concertadass. «Wall me dijo en el tono alegre que le es familiar que habia yo puesto en movimiento a toda Inglaterra y leyó enseguida parte de los pliegos de Abreu (que fue muy aplaudida) que contenia la conversación de los ministros del rey con él, con motivo de mi informe acerca de las operaciones que proyectaban hacer los españoles en las Indias Occidentaless. Adviértase que Keene dice sinformes» y que hace referencia a la carta de Abreu. Es luego, cuando dice upuse, pues en manos de Wall un papel que no era otra cosa sino una copia exacta de las instrucciones dadas por el comandante de la escuadra de La Habana...); aqui, las órdenes no son de Ensenada sino de un "comandante de la escuadran. CoxE, G., España bajo el rinado de la casa de Borbón, desde 1700 en que subio al trono Felpe V, hasta la muerte de Carlos III, acaecida en 1788. Madrid, 1846. p. 402 y ss. También la selección de correspondencia de LODGE, R, Private Correspondence of sir Benjamin Keene. Cambridge, 1933.

31 Abreu, el embajador en Londres, que se dio cuenta de cómo se habia instrumentalizado su correspondencia, solicitó a Wall machiconamente pruebas de que Ensenada había

Hispania, LIX/1, núm. 201 (1999) 217-249 
Sin embargo, Duras, que desde principios de 1754 estaba eufórico por creer a su ganado Ensenada completamente inclinado a Francia y a una inevitable guerra franco-española contra Inglaterra, había tomado el asunto de las cartasórdenes como una prueba de la actitud prebélica del marqués, lo que en Versalles significaba su primer éxito. La primera vez que habla de ellas es el 24 de abril de 1754, pero ya desde enero escribe constantemente sobre los planes ofensivos de Ensenada y se entusiasma al hablar de lo seguro que está el ministro para la causa francesa. No es raro que todo esto llegara a oídos de Keene, como también creyó D. Ozanam.

En este clima de guerra que se prefigura, Duras llegó a enviar un estadillo con las descripción de todos los barcos que había en la matina española, incluso los que se estaban construyendo en los arsenales, siempte insistiendo en su fortaleza y en que Ensenada ha pasado a la ofensiva ${ }^{32}$. Ni siquiera cifra el documento. Lo que descubre, que para él representaba un éxito, para Ensenada supondria un grave riesgo del que es posible que se diera cuenta. Frecuentemente tenía que indicar a Duras que se vietan en privado y siempre le repetía lo que a todos: había que guardar el secreto de los planes en la marina, entorpecer con pequeñas acciones a los ingleses -incluyendo la diplomacia (contando con el conocido mal genio de Carvajal) - hasta que se estuviera en estado de "lui tenir tete», de hacerles frente con expectativas de éxito, lo que en verano de 1753 Ensenada pensaba que habría de llegar al menos dos años más tarde ${ }^{33}$. Jamás pudo pensar que estos éxitos, que iban a engrosar los de la casa de Borbón, pudieran volverse contra Francia y contra Ensenada.

En definitiva, la principal misión del embajador, el reforzamiento de la alianza francoespañola para hacer entrat a España en una próxima guerra, acabó no sólo fracasada sino con riesgo de que, al desaparecer Carvajal, la garantía férrea de la paz y por ello el obstáculo de los planes de Duras, y caído Ensenada, su principal valedor, ocurriera precisamente lo peor para Francia, con Wall y Huéscar en el poder. El embajador llegó a mostrarse desesperado y abatido al comprender su "terrible situation», como él mismo la definía: a la altura de agosto de 1754 veía inminente una guerra insegura y una corte adversa: Huéscar, enemigo de la casa de Borbón, fllobritánico y amante de Austria — no se olvide su

dado las órdenes de guerra que conocía por las cartas de Keene, referidas por el gobierno inglés, pero nunca tuvo respuesta. Sin otra información, cuando supo la caida del marqués, intuyó la trascendencia de su carta del 9 de julio y vio que había sido instrumentalizado. V. El proyecto reformista... , p. 144 y ss. Las cartas de Abreu a Wall de 9 de julio y de 15 de agosto de 1754, en AHN, Estado, leg. 4273.

2 «Los primeros meses de $\mathbf{1 7 5 4}$ revelaton el desartollo espectaculat de la matina de guetra española, actividad que, a los ojos de Keene y de su gobierno, sólo podía estar dirigida contra los intereses de Gran Bretaña». OzanAM, D., «La política exterior de España en tiempo de Felipe V y Fernado VIr. Historia de España de Ramón Menéndez Pidal, t. XXIX, vol. I. Madrid, 1985 , pp. 443-699, p. 678 .

33 AAEP., T. 512, N., Aranjuez, 26 y 27 de junio de 1753.

Ilispantia, LIX/1, núm. 201 (1999) 217-249 
nacimiento en el exilio vienés-, se le presentaba como el centro de las decisiones; Wall, probritánico y antifrancés, estaba a la cabeza de las relaciones diplomáticas; y todo el ensenadismo, que por exclusión era el único apoyo de su causa, estaba destrozado, con sus principales cabezas en el destietro y los que quedaban en la corte - Rávago y Farinelli-a un paso de caer en la desgracia, como pronto iba a ocurrir. Sólo le quedaba el rey, la sangre borbónica y a ella apeló desesperadamente.

\section{LAS INTRIGAS EXTRANJERAS EN YA CRISIS DE JULIO}

En la Europa del precario equilibrio de Aquisgrán, la caída de Ensenada se unió naturalmente a un forzoso desequilibrio del sistema de "guerra sorda", como calificaba Carvajal al precario periodo de paz en que todo el mundo quería la guerra. La "crisis de julio", la más seria en la política hispanofrancesa desde la expulsión de la Utsinos cuatenta años antes, fue para el mundo diplomático la señal de que Inglaterra había ganado la gran baza de Madrid. De todas las embajadas se recibieron noticias sobre temores de los ministros ante la inminencia de la guerra, lo que contribuía a airear que Francia recibía un duro golpe al perder al que se consideró siempre el principal fancófilo de la corte española. Véase como ejemplo la reacción de Puentefuerte desde Estocolmo:

«La noticia que VE se digna comunicarme de la caída y prisión del marqués de la Ensenada ha causado aqui a más de la sorpresa y mucho temor de que no padeciese interrupción el sistema de estrecha unión con la Francia; y el embajador del rey Cristianísimo es uno de los sobresaltados" ${ }^{34}$.

La embajada inglesa se atribuyó un papel todavía más relevante en la conspiración, lo que no era sino una maniobra más de coronación del éxito; para reforzarlo y presionar más en el mundo diplomático, el embajador hasta fue condecorado. En Londres se llegó a idear que fuera el propio Fernando VI el que le impusiera la orden del Baño, una maniobra que pretendía explotar el efecto exterior, la difusión por toda Europa de la posición de fuerza del gobierno inglés, lanzado ya al dominio del mar y a la presión imparable sobre las Indias españolas. El «no se construirán barcos» que Keene dijo ${ }^{35}$ en medio de la euforia del 20 de julio fue una premonición de cual iba a ser el escenario de la próxima guerra.

La actuación de Duras y, en general, de los ministros franceses, contribuyó más si cabe a aumentar los temores de ruptura de la neutralidad española en favor de Inglaterra, lo que, sin embargo, no se produciría durante el reinado del "trey pacífico» ni siquiera en el periodo de gobierno del sucesor de Carvajal, el tan temido por anglófilo, Ricardo Wall, que se prolongó hasta después de llegar

34 AHN, Estado, leg, 6512, Estocolmo, Puentefuerte a Masones, 3 de agosto de 1754.

35 Con todo, la conocida frase es de una carta tardía, de 31 de julio, de Keene a Robinson. Cfr. Coxe, G., España bajo al reinado.. p. 402 y ss. Véase también Lynch, J., EI Siglo XVIII..., p. 166.

Hịpania, LIX/1, núm. 201 (1999) 217-249 
Carlos III ${ }^{36}$. El irlandés Wall no llevó a España a la guerra, ni rompió la alianza francoespañola y Duras pasó por asustadizo. Teorícese lo que se quiera sobre los centros de decisión y sobre las filias y fobias de los ministros, pero todo alto cortesano medianamente enterado sabía que Fernando VI no se alinearía nunca contra Luis XV. Ensenada, harto de los temores de Duras, se lo declaró así al embajador en mayo de 1754, secamente: "Le roy apris son parti et est plus francois aujourdhui que son pere ne l'a jamais etés. Duras añadió después que no había visto nunca tan franco al marqués ${ }^{37}$.

Lleva toda la razón Céspedes del Castillo cuando afirma «pronto resultó evidente que Francia utilizaba esa ahianza en su exclusivo beneficion; sin embargo, a causa de la neutralidad gubernamental, excluye el reinado de Fernando VI de la estrategia general de los Pactos de Familia, que define certeramente así:

«...más como un medio de desviar la posible agresividad francesa que de obtener una ayuda leal y eficaz contra los británicos; más para neutralizar un posible enemigo que para lograt un improbabale amigo» ${ }^{38}$.

En efecto, así pensaban Carvajal y Wall, que nunca se fiaron de Francia y menos de que España estuviera en condiciones militares de ir a una nueva guerra, pero no Ensenada ni el propio rey, por más que quisiera representar el papel. Ensenada conocía muy bien que la perfidia era la base de las relaciones diplomáticas y no se lamentaba, como hacía Carvajal, cuando se hacía evidente en la práctica política, como ocurrió en la guerra - y en la paz- anterior. Por eso pensó que para que Francia se mantuviera leal en la alianza contra Inglaterra no valían los tratados ni la sangre de los monarcas; conocía bien que la grandeza francesa heredada de Luis XIV, al que reverenciaba como todos los déspotas, persistía y que en Versalles se consideraba a España como un país subordinado y en decadencia. Era necesario, pues, estar en una situación militar poderosa y eso, ante Francia, imbatible en tierra a causa de su numerosa infantería, exigía tener una gtan marina de guerra. El rey sólo temía la derrota: nunca pudo estar seguro de que Francia y España unidas fueran superiores a Inglatetra. Le bastaba la experiencia anterior y, por más que le asegurara Ensenada que había que esperar unos años, tenía al lado a Huéscar y a Carvajal que nunca creyeron en la viabilidad del proyecto del marqués.

Ensenada había pensado el refuerzo naval como un verdadero plan de movilización en el que empleó todos los medios, técnicos, humanos y militares. Su gtan preocupación inicjal fue aumentar el número de marineros, muy escaso cuando entró en el ministerio. «Lo que me martiniza - escribió en 1748- es la poca marinería que

36 Sobre las fobias y filias infundadas, v. E/ proyecto reformista... Con todo, reproduciré unas ilustrativas palabtas de Carvajal sobre el «anglófilo» Wall: "esté V. S. seguro de que Wall nada será, sino es to que sea su amo, si el roy fuere francés to será y si el rey fuere inglés to será él, sin extraviarse a otro lado\%. AGS, Estado, leg. 6913. Carvajal a Tabuérniga, 17 de junio de 1748.

37 AAEP., T. 515, SC., Aranjuez, 13 de mayo de 1754.

38 CÉspedes Del Castillo, G., «Ámérica en la monarquía,, Actas del Congreso internacional sobre "Carlos III y la Ilustración», T. I, Madrid, 1989, p. 106.

Hipania, LIX/1, núm 201 (1999) 217-249 
tenemosy Esta era la causa de los fracasos navales anteriores al 1748 y sabía que era conocida por los ingleses. Keene aparentaba tranquilidad sabiendo que Ensenada podría tener barcos pero «en muchos años no puede tener un marinero». Así, empleó el dinero de la recluta en engrosar la matinería -incluso desatendiendo al ejército, de lo que luego sería acusado, con razón-; aseguró sus pagas, mejotó la formación de oficiales y aumentó en cantidad y calidad la mano de obra técnica, fomentando el espionaje en el mismo Londres y trayendo ingenieros ingleses a base de toda clase de peripecias (algunos conservaron su religion protestante en la España de la Inquisición y del tenido por (jesuitón» Ensenada). Al ejército envío a los vagos. Con todo, en Inglaterta persistían las ideas de fracaso que Keene trnsmitia: stodos estos proyectos se desvanecerán en grandes gastos sin llegar a ninguna ejecucións ${ }^{39}$.

Duras llegó pensando igual del irrealizable proyecto naval. Vaulgrenant, el anterior embajador, y el ministro Puyzieulx estaban convencidos de que

\&l etoit essentiel que les deux couronnes travaillasent promptement et efficacement a retablir leur Marine, donc la faiblesse leur avoit eté si perjudiciable pendant la guerre precedent (...) Mais M. le marquis de Puyzieuls pensoit comme Carvajal qu'il vaudtoit mieux construire des vaisseaux peu a peu et successivaments.

No veían posible construir cincuenta barcos a la vez como quería Ensenada; no habría materiales, pero aún sería más dificil use procurer un nombre suffisant d'ouvriers pour une entreprise aussi entendues ${ }^{40}$.

Así se pensaba en 1751, cuando los arsenales eran ya un babel de ingleses, franceses, holandeses, italianos y mano de obra rechutada entre vagos, soldados y naturales. En las cercanías de los arsenales se llegaron a producir protestas de los propietarios que se quedaban sin trabajadores y sin animales de trabajo. Duras conseguiría conocer al poco de legar que el rearme naval era ya un éxito rotundo y que Ensenada estaba eufórico, aunque todavía prefería el secreto.

La primera ocasión interesante se le presentó al poco de llegar a Amnjuez, en mayo de 1753. En una conversación con el manqués éste le confiesa su odio por los ingleses y que en dos años estarí en situación de desafiarles (les braver) en América. A juzgar por las expresiones de Duras, Ensenada ha logrado superar la desconfianza de Carvajal, los celos entre los dos continuan, peto Ensenada «il a totalment pris le dessus» ${ }^{41}$. Con todo, aprecia el desagrado que Fernando VI le muestra a Ensenada, seguramente a causa de quejas de Carvajal ya referentes a los primeros indicios de la política ensenadista en las Antillas que el Secretario de Estado interpreta como riesgos de su sistema, el que ha hecho de Fernando VI el «árbitro de la paz».

39 Exposición sobre fomento de la Matina... 1748, en FernândeZ Duro, C., La Armada española desde..., pp. 377-378. Sobre las opiniones de Keene, OzANAM, D., «La política exterior de España...), p. 466 y LODGE, R., Private Correspondence of sir Benjamin Keene. Cambridge, 1933. Sobre espionaje y técnicos ingleses, v. El progecto reformista..., cap. III, 4 y la bibliografia que se aporta.

40 AAEP., Memoires et documents, T. 345, 28 de enero de 1751.

41 AAEP., T. 512. N., Aranjuez, 6 de mayo de 1753. En otra de 15 de mayo: «M. de la Ensenada, ce ministre a la superionté entier et a disipé les orages qui semblaient formés contre lubs.

Higpantia, LIX/1, núm. 201 (1999) 217-249 
El trato con el marqués se fue haciendo más asiduo y al final de la estación de Aranjuez del 53 le confesará que no había que temer por Carvajal, pues en adelante «sería francés». Después Ensenada le confiesa que había escrito a Wall a Londres para que le dijera al gobierno inglés que quería la paz pero que no temía la guerra ${ }^{42}$. En efecto, al poco se empezaban a producir los apresamientos de barcos ingleses en la costa de Honduras. El 10 de mayo Wall comunicaba a Carvajal que los periódicos ingleses traían la noticia de combates en Campeche ${ }^{43}$. Iban a empezar las quejas de Keene ante Carvajal, lo que tanto temía el prudente ministro y lo que esperaba Ensenada.

Porque Ensenada estaba seguro de que Carvajal se abrumaría por las protestas de Keene y acabaría viendo que el verdadero peligro de guerra estaba en la hostilidad inglesa en América; testarudo como era, cuanto más presionatan los ingleses, más riesgo vería en ellos. En efecto, en noviembre de 1753 le decía a Wall: "no se puede ceder; no tienen más derecbo que los ladrones para burtar) ${ }^{44}$. Veía todo en clave altamente motal y temeroso de que su sistema de paz naufragara - «la tempestad va a rompeny, decía en verano de 1753-, acabaría por irritar a los ingleses, que es lo que buscaba Ensenada. Además, en Carvajal Ensenada tenía un crítico tenaz de sus proyectos de guerra naval, lo que era un reaseguro para sus proyectos secretos. «Reniego de Marina que tan malamente nos ba servido en una guerra de mar, babiendo consumido millones sin término y perdido vasos por insensible transpiración’, decía Carvajal al conocer los desastres de 1748 . Y, opuesto a la estrategia militar de Ensenada, escribía: «bácese bulla de bacer navios e introducir comercios (sin conocimiento) y yo persuado lo contrario: que se esté el ejérrito a ver si nos dan la posesión, que nada se reforme, si sólo no recluten por el aborro, y que bagamos que no podemos y que es preciso sujetarnoss ${ }^{45}$.

Ya a principios de 1754 Duras había visto claro el juego de Ensenada y se aprestaba a sacar partido:

«Pour parvenir a un traitté solide il faut necessairement la guerre, elle ne peut s'eviter, il faut dont tacher. de la faire avec avantage»

Sabía que no hacía falta convencer de la inminencia de la guerta a Saint Contest, pues el ministro le había dicho meses antes:

ul est evident que la nouvelle colonie des anglois a Mosquitos occasionnerá infailliblement une guerre et meme prochaine entre l'Espagne et l'Anglaterre" ${ }^{46}$.

Lo importante era dar a conocer a Versalles donde estaba la «ventaja» de la alianza. Por eso, se volcó en demostrar que Ensenada preparaba ya proyectos

42 AAEP., T. 512.N., Aranjuez, 27 de junio de 1753.

43 AHN, Estado, legs. 4277-1, Wall a Carvajal, 10 de mayo de 1753.

44 AHN, Estado, leg. 4277-1. Carvajal a Wall, 8 de noviembre de 1753.

45 En Ozanam, D., La diplomacia de Fernando VI..., pp. 422 y 357.

46 AAEP., T. 515. Saint Contest a Duras, Versalles, 14 janvier 1754.

Hisponia, LIX/1, núm. 201 (1999) 217-249 
ofensivos y hacia demostraciones de fuerza ante Inglaterra. En marzo de 1754 Duras creía firmemente que Ensenada buscaba el enfrentamiento:

«al m'a encore repeté aujoutdhuy que tout ce qu'il desiroit etoit que l'on en vint a une rupture. J'ay cru voir clairement qu'il le souhaitoios ${ }^{47}$.

El secretista Ensenada había dejado ver la fuerza que escondía y Duras pudo trasmitir a Versalles que la marina española era ya mucho más poderosa de lo que decía Ensenada ${ }^{48}$. Para demostrarlo no dejó de trasmitir datos que avalaran su idea y hasta envió a Versalles amplia información sobre la situación naval española. Según un informe de abril de 1754 - un estadillo perfectamente caligrafiado al que ya hemos hecho referencia-, había en los puertos 85 barcos de guetra en total, entre los que ya estaban en uso y los que estaban en construcción avanzada. Sin embargo, a Versalles todavía le parecieron pocos para poder entrar en una guerra con Inglaterra, según pudo saber Duras por las confidencias de Noailles ${ }^{49}$.

Al saber que se había suscitado una consulta en el Consejo de Indias por la cuestión de Honduras y a la espera del resultado, Duras confesaba a Saint Contest «j'ai promis cinquente pistoles d'or et j'espere reusin ${ }^{50}$. Obtuvo copia de dos informes del fiscal y los envió, sin traducir, a Saint Contest. En efecto, la reacción en Indias fue durísima contra Inglaterra. En Versalles se imaginaban alborozados el color con que Keene pintaría el asunto a su gobierno, mientras Duras se afanaba en enviar noticias sobre la desesperada situación de Keene. En febrero, el embajador inglés salía de una larga conversación con Carvajal con mal semblante y se encerraba en casa. En marzo, Carvajal despachaba con el rey sobre las pretensiones de Keene; la respuesta no puede ser más hostil:

«Le roy lui avoit repondu que jamais il n'essui croit la moindre hauteur de la part des anglois, qu'il sacrifieroit jusqu'a son dernier ecu et son dernier sujet plutot que de se laisser maitriser par les vrais ennemis de sa maison; que en consecuence il pouvoit emploir le meme ton avec l'ambassadeur d'Anglaterre» ${ }^{51}$.

Las reacciones antibritánicas se aprecian también en las legaciones extranjeras en Madrid:

«M. Keene qui venoit beaucoup chez moi y paroit rarement)(...) (il se plaint surtout de $M$ de Carvajal qui lui a manqué de parole, et sur le quel on ne peut jamais compter Le confesseur fait fermer sa porte a $M$ de Migazzi (embajador de Viena) et Farinelli ne y fuit aucun cass.

En esas circunstancias, un acontecimiento viene a aumentar la escalada de la tensión: Duras ha recibido las primeras informaciones desde Versalles sobre

47 AAEP., T. 515, SC., Madrid, 20 de marzo de 1754

48 AAEP., T. 512. N., Aranjuez, 27 de marzo de 1754.

49 AAEP., T. 512. Noailles a Duras, Versalles, 18 de abril de 1754.

50 AAEP, T. 515. Duras a Versalles (s.d.), Madrid, 2 enero de 1754.

51 AAEP, T. 515. SC., Madrid, 9 de marzo de 1754.

Hippantu, L.JX/1, núm. 201 (1999) 217-249 
la salida de una escuadra inglesa con destino desconocido, pero que se piensa va a América a buscar un puerto donde establecerse y proteger militarmente a los buques que comercian con el palo de Campeche. Cuando informa a los dos ministros, Carvajal se asombra porque Wall, el embajador en Londres, no le ha dicho nada y no lo cree, mientras Ensenada le confia que sabe que, en efecto, se dirigen a las Antillas y le dice que ya ha tomado medidas:

«Despuis huit mois on fait partir des troupes, des officiers et des munitions de toute espece pour Catagene et $\mathrm{L}_{\mathrm{a}}$ Havane. Il vient de s'embarquer un marechal de camp nommé Amat que l'on dit etre tres bon officiens ${ }^{52}$.

Dos semanas después, logra saber que Carvajal se ha distanciado de Ensenada más que nunca y teme lo peor: la guerra. El secretario de Estado cree que todo lo que pasa es un nuevo montaje exhibicionista de Ensenada y se atreve a desvelar ante el rey que muchas de las alarmantes informaciones son falsas y sólo tienen por objeto provocar la ruptura con Inglaterra. Es la primera vez que Carvajal llega hasta el rey con una gravisisma acusación contra Ensenada:

«ll fit entendre a sa majesté catholique qu'il etoit fort a craindre que l'escadre angloise ne prit le vaisseau le Dragon dans sa traverse de la Havanne a Cadiz, et ne s'emparat des trente sept millions de notre monnaye dont il est chargé. Le roy lui repliqua qu'il ne le pouvoit croire, que jamais depuis que $\mathrm{M}$. de la Ensenada etoit en place semblable malheur n'etoit arrivé, et qu'il falloit qu'ils en conferassent ensembles.

Duras logra saber que los ministros se habían visto varias veces y que Banfi, la hechura ensenadista en Indias, ha trabajado con Carvajal durante dos horas y media. La situación es tan tensa que solicita a Versalles autorización para hablar con Carvajal y conocer las disposiciones del ministro en caso de que el'orage eclate contra nous» ${ }^{53}$.

El 20 de marzo puede informar con tranquilidad que Carvajal está volcado contra los ingleses e incluso que las relaciones entre los dos ministros han mejorado, lo que Saint Contest celebra. Keene no aparece por la corte, Carvajal no le habla y, por contra, Duras ha aumentado su estimación ante el ministro ${ }^{54}$. En esa situación se produce la muerte de Carvajal el 9 de abril.

Con inusitada rapidez todo parece cambiar. El mismo día que muere el ministro, por la tarde, Duras califica la situación de la corte de «bouleversements dans toutes les tetes». Sabe por Rávago que Huéscar será nombrado interinamente y que "está ganado para los ingleses y austriacos» y que «el odio a Ensenada es el nexo de la unión. El marqués está muy afectado, comienza a temer por su situación, pero sigue tenaz con sus planes en América. Duras le informa de que los barcos ingleses son catorce y que van a América con seguridad. Consigue saber que ha enviado ór-

52 AAEP, T. 515. SC., Madrid, 23 de febrero de 1754.

53 AAEP., T. 515. SC., Madrid, 9 de marzo 1754.

54 AAEP., T. 515, SC., Madrid, 20 y 26 de matzo y 1 de abril de 1754. La tespuesta de Saint Contest, de 26 de marzo.

Higpania, LIX/1, núm. 201 (1999) 217-249 
denes ofensivas a América, pero le sabe en riesgo y víctima de un formidable complot. A partir de ahora y hasta la llegada de Wall, nada trascenderá sobre el problema de las Antillas. La muerte de Carvajal parece que ha paralizado todo.

La primera entrevista entre Duras y el sucesor de Carvajal, Ricardo Wall -Dick, para Keene (el caballero Wall era irlandés) - celebrada el 17 de junio de 1754 , es una muestra de prudencia y de maneras cortesanas. El que ha sido durante muchos años embajador en Londres dice no saber todavía nada del problema de la escuadra inglesa y de la situación en América; debía leer los papeles de la secretaría de Carvajal, lo que todavía no había hecho, y a las preguntas de Duras sobre sus disposiciones en caso de rurptura de hostilidades, contesta que no sabe lo que habrá de hacerse en el futuro y que sobre eso no hablará. Para dejar más intranquilo a Duras le llega a decir que los ingleses sólo tienen un conocimiento vago de lo que pasa en Mosquitos. La conclusión de Duras no puede ser más que ésta:

«je crois voir dans $\mathrm{M}$. Wall un gout pour la nation angloise, qui prend sa source dans totutes les politesses et les atentions qu'on lui a temoignees pendant son sejour a Londres; les moeurs des anglois etant assez analogues a celles qu'il a toujours practiquées. Il se plaisoit avec eusos ${ }^{5}$.

Como Duras había pensado, Wall, al que todavía cree amigo de Ensenada, se mantendrá firme ante los ingleses set dissimulera plus long temps les irregularités de leur procedéss. Pero el embajador seguía creyendo que Ensenada era dueño de la situación a pesar de todo. Una buena prueba era para él que Keene no pisaba la corte y que tenía pensado abandonar Madrid (así lo creía o se lo hicieron creet) ${ }^{56}$. Como su referencia era el «humop» del embajador inglés, podía hacer una descripción tan halagüeña:

«Il paroit que la position de $\mathrm{M}$ de la Ensenada se raffermit tous les jours et l'on en peut juger par la tranquilité que regne sur son visage et sur celui de ses amis; ses antagonistes abbatus et consternes son un motif de plus pout croire qu'il a repris le dessus» ${ }^{57}$.

¿Qué ocurre en menos de un mes para que todo cambie?

Huéscar había sometido al rey a una constante presión contra Ensenada. Venía ya desde principios de año, se recrudeció a la muerte de Carvajal y fue ya pública en junio y julio. Sin embargo, el rey era incapaz de autorizar un giro que pudieta malquistarle con sus primos franceses, ni siquiera apelando a su «españolidads como hacía Huéscar:

55 AAEP., T. 515, SC., 17 de junio de 1754.

56 AAEP., T. 515. R., Aranjuez, 26 de junio de 1754. Ha logrado saber que en la embajada inglesa se teme la partida de Keene por las confidencias de una mujer de la que está enamorado el secretario del embajador. Lo más seguro es que esta confidente le engañara a propósito o se dejara llevar por sus temores de enamorada.

57 Ibid., 19 de junio de 1754. 
«M. de Huescar, qui paroit vouloir gouverner M. Wall, ne se cache plus de son attachement pour les cours de Londres et de Vienne; il s'est declaré presque ouvertement leur avocat, il fuit cent plaisanteries sur la France et la destruction de l'empite que nous voulions etablir sur l'Espagne: que le temps de l'aveuglement est passé et que les espagnols vont voler de leur proppes aisles» ${ }^{58}$.

El duque de Huéscar conocía las inclinaciones de Fernado VI, así que para hacerle cambiar de opinión le presentaría los planes de Ensenada no sólo como causantes de una guerra, sino además como abocados al fracaso. A mediados de junio, Huéscar había logrado conocer las alarmantes cartas que Keene iba a enviar a Londres y esperó la respuesta. Esta vendría tanto del gobierno inglés como del embajador español en Londres, Abreu. En efecto contenían lo que Huéscar buscaba y lo que pudo saber Duras: la crisis diplomática había estallado. La misma tarde del 20 de julio el embajador había visto a un Wall crispado, que le reprochaba su comportamiento, y poco antes a Valparaiso, que le dijo que todo lo que pasaba lo veía con pena y que no queria ser testigo. Ensenada, por contra, le había dicho tres días antes que estuviera tranquilo.

\section{LA CAÍdA DE ENSENADA, EN LOS PAPEIES DE DURAS}

Pasadas las doce de la noche del sofocante 20 de julio de 1754 en Madrid, una treintena de guardias obedecían las órdenes que Ricardo Wall y el duque de Huéscar habían dado personalmente en nombre del rey al coronel del regimiento de Guardias Españolas marqués de Sarria, hermano del difunto ministro Carvajal, y se presentaban en casa del marqués de la Ensenada, secretario de Estado de Hacienda, Guerra, Marina e Indias, para artestarle y conducirle inmediatamente a una diligencia en la que, sin detenerse y con la sola compañía de dos oficiales, Rojas y Jarrabeitia, que tenían orden de custodiarle, debía llegar a Granada y presentarse ante el presic'ente de la Audiencia, que le daría por cárcel la ciudad.

Poco más pudo saber Duras al día siguiente. Estaba incomunicado y realmente asustado. Creyó firmemente que la guerra podía estallar en cualquier momento. Los pasquines que había podido recoger y enviar a Versalles - una semana después-, unos populares y populacheros, pero otros dirigidos desde muy arriba, como los que se referían a la corrupción del ministro y sus colaboradores, decían que el que había sido todo era ya nada. «Mucho ense, mucho ense, ahora nada», "En-sí-nada», desterrado en «Gran-nada» y desnudo como Adán (al revés, nada). Ninguno se refería a la política intenacional.

Los autores de la conjuración, Wall y Huéscar, tuvieron que justificar un acto que causó asombro no sólo en Madrid sino en todas las embajadas extranjeras en la corte y, cuando llegaron los correos, en las capitales europeas, sobre todo en Londres y París. Inmediatamente se desató la alarma de guerra y los rumores, algunos disparatados, abonaron la incertidumbre:

58 Ibid, 20 de julio de 1754.

Hippania, LIX/1, núm. 201 (1999) 217-249 
«Depuis Dimanche il regne une inconsecuence dans toutes les demarches de la cour que surprend et indigne tout le monde (...) les gens sages et vrais espagnols se desesperent, les financieres disent qu'ils ne fourniront pas un sol et les marins se regardent comme perduss ${ }^{5}$ ).

Duras aparentó asombro, pero un mes después de la muerte de Carvajal ya había hecho pronósticos certeros sobre la suerte de Ensenada:

(tot ou tard il y aura quelques victimes sacrifies et tout est a redouter pour mr. de la Ensenada que le roy n'aime pas, et qu'il ne garde que par necessité. Ce ministre ne se conduit pas a la facon a le ramener; il affiche peu d'attachement pour sa place et ne s'occupe point a parer les coups quil'on lui portes ${ }^{60}$.

Aunque es a partir de ahom cuando Duras repara en la aversión que sentían los grandes contra Ensenada —eta una teflexión que su amigo Noailles ya le habia trasmitido en mayo del $54^{61}$, , desde enero la inquina de Huéscar contra el hidalguillo medrado era ya pública. Pero Carvajal era grande de España, noble por ascendencia española - un Abrantes-m, inglesa - un Lancáster - y portuguesa - ue o sangue que tem Portuguez e em que mais fio o seu bom procedimenton, decía la reina- ${ }^{62}$, y le respetaban todos. A pesar de sus variables relaciones con el marqués y de las frecuentes irritaciones que producía su comportamiento, incluso al rey, Carvajal sólo tenía celos de Ensenada ( $y$ eran fundamentados). Le había suplantado en el concordato, llevaba una política exterior paralela, le ocultaba asuntos y le desesperaban su pompa y su doblez, pero debió creer sinceramente en su inteligencia y en su disposición a entregarse lealmente al servicio del rey y eso era para Carvajal el fundamento de la restauración española en la que creía firmemente ${ }^{63}$. Por eso, mientras vivió, Ensenada estuvo seguro. En el otro extremo, don José conocía la veleidad de Huéscar, su altanería y hasta su zanganería. Con esa fama llegó de su embajada en París: para los diplomáticos parisinos era sfort ignorant et de peu de tratcaibs y para el ministro Argenson lo único que había hecho era aprovechar el Carnaval, levantarse muy tarde y no faltar a la Opera ${ }^{64}$. Pero Huéscat era un Alba que enlazaba hasta con el Conde Duque, tenía todas las condecoraciones, el Toisón y el Sancti Spiritus, y era lugarteniente del rey en los ejércitos. Sobre su visión de la nobleza no hay duda: uarrimate a buena sangres, le había dicho a Carvajal, y sobre su utilidad política, en un tiempo en que ya los nobles eran criticados abiertamente, decía: «la juventud noble podría

59 AAEP, t. 515, Madrid, R, 27 de julio de 1754.

6 Ibid, 13 de mayo de 1754 .

61 Nosilles vio el orgullo de los grandes csubordinadon a un plebeyo exitoso. Vid. infra y conclusiones

(2) Cit en GÓMEZ MOLLEDA, M.D., «Un rey sin gusto...», p. 83.

63 GÓMEZ MOLEDA, M.D. «El pensamiento de Carvajal y la politica intemacional española del siglo XVIII). Hiipania, 15 (1955), pp. 117-137. V. también sus preciosos artículos en la revista Eidos. Sabemos por Duras que Ensenada pudo hablar largamente con Carvajal antes de que éste agonizara. El marqués salió realmente afectado de la cámara donde a las pocas horas iba a morir Carvajal.

64 Ozanam, D., La diplomacia de Fernando VI..., p. 10, y Bouvier, R. et Soldevilla, C., En senada et son temps. Le redressement de l'Espagne au XVIII siècle. Paris, 1941, p. 61. 
proporcionar al reino muy naturalmente el personal dirigente que le faltas ${ }^{65}$. A pesar de eso, Huéscar iba a pasar por uno de los ilustrados volterianos del reinado de Carlos III.

Cuando se supo en la corte que el elegido para suceder a Carvajal era definitivamente Wall, se produjo un inmediato rechazo. Rávago se escandalizó aparentemente porque Wall era extranjero, así además unia su oposición a la de algunos grandes como Montijo y Albuquerque; pero, en realidad, techazaba la fama de antijesuita que rodeaba a Wall. El mismo rechazo muestra la reina Bárbara e incluso el pueblo que, según Duras, no quiete a un irlandés. El rey parece que puede cambiar de opinión. Incluso se hace venir de Holanda a San Gilles, "que l'on fit venir d'Hollande pour etre ministre et qui en debarquant trouva la place donné a un autres. Sin embargo, se produce el nombramiento de Wall. La reina se desconsuela por el triunfo de la intriga de Huéscar y el rey se encierra en sus habitaciones. Duras piensa que Wall ha tenido un valedor, Valdeparaiso, y que el nuevo ministro, del que cree ingenuamente que es amigo de Ensenada, será gobernado por el marqués. No sabe que la relación de Huéscar con Wall viene de muy lejos y que era el duque quien le había «descubierto»: «mira --le decía a Carvajal en 1747-, que en el ejérnito tienes una cosa muy buena que es Wally 6 .

Como habia hecho en 1746, Ensenada fingió estar contento del nombramiento de Wall ya que no podía evitarlo. Se ha especulado con sus presiones para que el rey nombrara a. Ordeñana, pero no he visto una sola prueba ni creo que pudiera llevar al rey una propuesta así en su situación. Ensenada conocía perfectamente su debilidad, intuía «la tormenta» - hacia unos meses que el término «orage» aparecía constantemente en las cartas del embajador francés Duras y en su conversación íntima con el ministro ${ }^{67}$ - y llegó a saber que esta vez ni la reina lo sostendría. La situación se tornó tan arriesgada para el ministro que Duras pensó que incluso había perdido el favor de Rávago.

En Versalles se desató la alarma. Saint Constest lamentaba la (position incertaine») de Ensenada y aseguraba que Francia perde í mucho si era desplazado " $"$. Lo mismo debieron pensar los «afligidos» de San Ildefonso, entre los que Ensenada tenía el favor de muchos cortesanos y de la propia reina viuda Isabel Farnesio. El cambio

6.5 Huéscar a Carvajal, 14 de mayo de 1747, en Ozanam, D., La diplomacia de Fernando VT..., p. 194 y p. 76. Una crítica a la nobleza, en Campillo, J., Lo que bay de más..., una obra muy difundida en ese momento. Cfr. la edic. de Elorza, Madrid, 1969, espec. las pp. 50-51.

64 Huéscar a Carvajal, 14 de mayo de 1747, en OzanAm, D., La diplomacia de Fernando VI. Correspondencia reservada entre don José de Carvajaly el Duque de Huéscar, 1746-1749, Madtid, 1975, p. 193.

67 Por ejemplo, ya en enero: «L'orage que s'etoit formé contre lui (Ensenada) etoit violent». AAEP., T. 515, SC., Madrid, 2 de enero de 1754. Más adelante, llegará a informar sobre las presiones que sufre para que participe en el complot contra el marqués, p. ej., en abril, confidencialmente a Noailles, su amigo, «La constance avec laquelle j'ai refusé d'entrer dans el complot formé contre mr. marquis de la Ensendan. Madrid, N., 9 de abril de 1754.

${ }_{6 B}$ AAEP., T. 515. Saint Contes a Duras, Versalles, 31 de mayo de 1754.

Hiptratia, LIX/1, núm. 201 (1999) 217-249 
que se teme del todopoderoso Huéscar es tal que el 4 de mayo Duras recibe una carta firmada por la Farnesio:

"Y siendome sensible que el quebranto de vuestra salud sea el principal motivo de no acercaros por aqui, os aseguro de nuevo hallaréis siempre propenso mi animo a concurrir a cuanto sea de vuestra satisfacción» ${ }^{69}$.

La carta está escrita bajo un pretexto, pero es un indicio de que ante la situación contaba el papel de los más acérrimos partidarios de Francia y de Ensenada. Isabel Farnesio no habría olvidado el papel de Huéscar en 1747, cuando el duque, al enterarse de que habían sido «desterrados» a San Ildefonso, decía de la reina viuda "go La quisiera en Parmas ${ }^{70}$.

Durante junio y julio, Huéscar fue acercando a Wall a sus planes mientras sometía al rey a una constante presión. Buscó la amistad del embajador de Portugal, fuertemente enfrentado a Ensenada por la cuestión del Tratado de Límites, y a través suyo el acceso a Bárbara, mientras Wall atraía a Farinelli: «M Wall quäl ne quitte pas aux genoux de Faninelliv, decía Duras a mediados de junio ${ }^{71}$.

Ensenada, efectista como era, presentó la dimisión al rey. Sabía que nadie le podía sustituir y que el rey no se atrevería a agrandar el boquete que había dejado Carvajal. Teatralmente, Ensenada podía mostrar una vez más el éxito de su maniobra y al poco hacer que los embajadores y los cortesanos pensaran que habia reconquistado el favor regio y dominaba la situación:

edl paroit que la position de $\mathrm{M}$ de la Ensenada se raffermit tous les jours et l'on en peut juger par la tranquilité que regne sur son visage et sur celui de ses amis; ses antagonistes abbatus et consternes son un motif de plus pour croire qu'il a repris le dessuss.

Pata Duras, «M. $d$ Huescar, desesperé, ne se tient pas pour battu», mientras la teina, el confesor y Farinelli han hecho comprender al rey que sólo el odio guiaba a los enemigos del marqués ${ }^{72}$. Para culminar el acto Ensenada habia enviado un memorial en el que rechazaba todas las imputaciones. Duras había podido saber algo de lo que Huéscar le decía al rey contra Ensenada:

(dl emploi tout son credit pour jetter de la mefiance et des soupcons dans l'esprit de son maitre (el rey) et lui represente un desordre general dans les finances et un deperissement total dans les troupes de terre, cet article a bien quelque fondement, une monopole affreuse dans toutes les bureaux des emissaires subalternes et gagnés confiment ces rapports et animent encore sa majesté catholiques ${ }^{73}$.

69 AAEP., T. 515. Isabel Famesio a Duras, San Ildefonso, 4 de mayo de 1754.

70 En GOMEZ MoLj.EDA, M.D., «El matquées de la Ensenada a través de su correspondencia íntimas, en Eidos, 2 (1955), p. 63 .

71 AAEP., T. 515, Aranjuez, 19 de junio de 1754.

72 Ibid., 19 de junio de 1754 .

73 Ibid., 13 de mayo de 1754 
A lo que además había que unir el Tratado de Límites, las relaciones secretas con el rey de Nápoles y con San Ildefonso, el ofrecimiento del capelo cardenalicio - que Ensenada pensó en su destierro de Medina del Campo que había sido la causa real de su caída ${ }^{74}$ - incluso asuntos de desvío de dineto a sus arcas y a los de sus hechuras - de ello tesultarían acusados Pérez Delgado y Orcasitas, por ejemplo ${ }^{75}$ - y aún críticas al desmedido lujo del marqués.

Duras, sin embargo, iría al fondo de la cuestión, como había hecho ya Noailles. Tras la caída, meditó sobre las razones profundas y vio que el marqués había arriesgado:

«enemi des grands qu'il avoit abaissez, mal avec les grands officiers qui n'avoient plus aucune authorité dans l'exercice de leurs charges, ayant indisposé contre lui ceux qui possedoient de grands biens et qui ne payoient rien le fardeau des imposts tombant entierement sur le peuple; plusieurs qu'il n'avoit pas regagnez pas de bienfaits particulieres avoient declaré contre luis) 76.

A mediados de julio, el clima de hostilidad contra Ensenada había hecho mella en los reyes, pero hacía falta que el taciturno Fernando se decidiera a desprenderse del ministro. Eso para la reina era caer en brazos de Huéscar, al que veía muy peligroso. Hizo falta un verdadero mazazo: el que produjeron las noticias provenientes de Inglaterra. Duras lo supo el mismo día de la caída. La larga carta que escribió durante todo el día 20, con interrupciones, salidas y conversaciones - una con el propio Wall-, demostraba que acopió buena información:

Il est arrivé un courier de Londres avant hier (el 18) qui a occasionné deux conferences hier (el 19) entre cet ambassadeur et le ministre; mais je ne sais point encore ce dont il a eté la question. Ce que j'ai appris, et qui pouvoit bien deranger encore plus le systeme de $\mathrm{M}$ d'Huescar, c'est qu'il y a quatre mois que les ordres ont eté envoyés a l'audience de Guatemala de rassembler jusqu'a trois mille hommes pour aller attaquer les anglois a Rio Tinto. Cette demarche sera un coup decisif, et je doute fort que la cour de Londres la souffre patiemment.

Duras sospechaba la relación secreta entre Huéscar y Keene, pero todavía el mismo 20 de julio por la mañana, cuando escribía la primera parte de esta

74 EcufA Ruız, S.J., P.C., E/Margués de la Ensenada, segin un confidente. Madrid, 1922.

75 V. El proyecto reformista.., especialmente la valiente declatación de Pérez Delgado, p. 195.

76 AAEP., T. 515. R, Madrid, 14 de agosto de 1754. Salvo en un pasquín popular, que hace del catastro (cremedio del necesitado, polilla del hacendado», no hay referencias a la oposición que despertaron el catastro y las medidas fiscales de Ensenada. En ello, reparó con notable exageración el sagastino Amós Salvador, riojano como el marqués, que hizo de él uno de los pocos retratos «diberaless que existen de Ensenada, pintándole como un salvador del pueblo pobre. Cfr. SALVADOR, A., E/Margués de la Ensenada. Discurso premiado en los juegos florales del A teneo logroñés. Logroño, 1885 . Sobre el clichet conservador de Ensenada, v. la introducción de $E$ l proyecto reformista.. $\mathrm{y}$, en general, OLAECHEA, R, «Política eclesiástica de Femando VI», La época de Fernando VI. Oviedo, 1981, pp. 139-226. Por supuesto, hay que recurrir también a D. Marcelino y a sus Heterodoxas.

Hixpunia, LIX/1, núm 201 (1999) 217-249 
carta, no podía imaginar el resultado. Pensaba que «M. de la Ensenada paroit dans ce moment joutir de la plus grande considerationy y que el rey le sostendría. Por la tarde, $\mathrm{y}$ tras un violento encontronazo en casa de Wall -uje ne crois pas que je me presse de retourner chez luijs, dice - retoma la pluma para dar cuenta de que la situación se agrava. Con notable expresividad escribe:

"Je marche perpetuellement sur les charbons et crain sans cesse de faire des faux pas»

La crisis es violenta, añade. Todo el mundo en la corte dice que los franceses van a la guerra contra Inglaterra y que arrastrarán a España.

El correo con esta carta salió a las ocho de la tarde hacia París, poco más de cuatro horas antes, por tanto, del arresto de Ensenada. Lo que pasó después corrobora la información que pudo tener Masones en París, donde la noticia de Ia crisis llegó antes que la siguiente carta que pudo enviar Duras. En efecto, como se sospechaba en París, al embajador le habían impedido escribir. No estaba preso como se creía, pero sí incomunicado. Cuando pudo escribir, jsiete días después!, se quejaba amargamente del trato:

यe vous aurois depeché sur le champ si j'en avois eu la permission mais les ordres les plus rigoreux etoient donnés a la porte pour ne fournit aucuns chevaux ceux qui en viendroient demander a moins qu'ils n'eussent un passeport de Mr. Wall signé du meme jour. Je ne fus pas du nombre des privilegiés, puisque ce ministre me le refusa quand je lui demandai si le roy son maitre trouveroit bon que je fisse partir un courier. M. l'ambassadeur d'anglaterre et celui de Portugal furent tmieux traités. Je etoit juste qu'ils eussent la preference puisqu'ils etoient dans la confidence de tout ce qui devoit arrivens. ${ }^{77}$

Podía ya explicar los detalles de lo sucedido: El rey había estado cazando hasta las 9 de la tarde, Ensenada había estado todo el día esperándole, pero el rey en vez de despachar con él le había dicho que estaba cansado y se retiraba a descansar. Duras supo por las damas de la reina que el rey estaba muy sombrío a la hora de cenar y que, en vez de tetirarse, cuando volvió de cazar con la reina se había encerrado con Wall, lo que no sorprendió. De ese conciliabulo con Wall, en el que estuvieron presentes la reina y Huéscar, salieron Wall y el duque con la orden de arresto firmada por Fernando VI.

Duras, que el día 20 por la mañana pensó sólo en las cartas que envió Abreu desde Londres como desencadenante de la determinación del rey, añadió días después otros motivos. No se le ocultaba que el origen de la trama estaba en la política inglesa, pero la complicó con una «conjura napolitana», quizás para evitar la exhibición internacional del éxito de los británicos y, sobre todo, de su rival Keene. Según Duras, Huéscar y Wall habían encontrado en los cajones del difunto Carvajal dos cartas de Ensenada enviadas a Nápoles en las que recomendaba a Carlos mantenerse frrme en el Tratado de Aranjuez y no ceder a las presiones y ofrecimientos, que no le faltarían, para separarse de Francia. El rey

77 AAEP., T. 515, R., Madrid, 27 de julio de 1754.

Hipparaia, J.JX/1, núm. 201 (1999) 217-249 
montó en cólera al ver las cartas y la reina exclamó que el proceder de Ensenada era un "crimen de Estado".

Sin embargo, es probable que este cargo no fuera definitivo, quizás sólo uno más, como meses más tarde el propio Duras reconocerá al inclinarse decididamente por la trama británica: el 1 de setiembre le decía a su amigo Noailles que el principal motivo de la caída del marqués fue

«a lettre de mr. Keene et l'ordre qu'il pretend que ce ministre avoit donné aux vaisseaux de l'Espagne qui sont a l'Amerique de courir indistinctament sur tous les navires qu'ils remontreroient faisant le commerce dan cette partie du nouveau monde et de de $s^{\prime}$ en emparess ${ }^{78}$.

Hay que desconfiar de la información que Duras tenía en julio e incluso de sus intenciones. La trama "napolitana» pudo ser una pieza de la contraconjuración francesa. Se ajustaba al carácter de Duras, que solía lanzar rumores sobre acciones antifrancesas para facilitar el refuerzo de las alianzas de Versalles. Muchas de sus informaciones provenían de San Ildefonso, del entorno de Isabel Famesio, que mantenía una cortespondencia permanente con Nápoles plagada de sospechas y que vivía anhelando la llegada de Carlos a España, pero esto era conocido por todos, incluidos los reyes. El abate Facundo Mogtovejo hacía de recadista en esa relación a favor de Ensenada y por eso, tras ser también detenido el 20 de julio, antes de ser desterrado, fue además interrogado. El abate había sido secretario de la embajada de Nápoles y oficiosamente seguía siéndolo; pasaba su vida en casa de Ensenada y se alojaba en la de la marquesa de la Torrecilla, dama de honor de la reina, a la que Duras, que debía conocer los rumores sobre las relaciones de Ensenada y esta mujer, enamorados en la juventud, llama todavía «maitrisse de Ensenada» ${ }^{79}$.

Es evidente que los rumores sobre la "conjura napolitana» tenían origen francés y que habían viajado desde la embajada francesa en Madrid a Versalles y de ahí a la embajada española en París. Masones se llegó a asombrar cuando conoció hasta donde habían llegado, pero cometió la torpeza de declarárselos, absolutamente agigantados, a Wall:

«la voz general se reduce a que se trataba por Ensenada y su partido (en que por consiguiente metían a mi juntamente con la teina viuda) la negociación de que nuestro Amo abdicase la Corona, entraba en ella el rey de Nápoles y pasase a aquella el infante duque de Parma, lo cual descubierto por la reina nuestra señora disuadió al rey que conoció los malos consejeros y prorrumpió en castigarlos ${ }^{80}$.

78 AAEP., T. 512, N., Madrid, 1 de septiembre de 1754.

79 Sobre este asunto no dice nada Gómez Molleda, pero hay una novela decimonónica tan absolutamente recomendable como dificil de conseguir: SomozA, J, E/ Capón, Avila, reed. 1977. Con todo, la Torrecilla hacía tiempo que estaba con tisis. Otro asunto era como estaba con Ensenada la duquesa de Salas.

80 AGS, Estado, leg. 4523. La minuta en AHN, Estado, leg. 6512.

Hispania, LIX/1, núm. 201 (1999) 217-249 
O Francia estaba desviando la atención de la trama inglesa en un intento de evitar el éxito diplomático británico o el embajador español se precipitaba, confuso y asustado, quizás en un intento de separatse del caído y bienquistarse con el nuevo gobierno. De Masones llegó a decir Choiseul que era el «mejor hombre del mundo, pero el más inepto ministro que baya babido nuncas ${ }^{81}$. Sobre Duras, los calificativos fueron parecidos.

La larga carta del 27 de julio contenía también información sobre los otros asuntos que les fueron presentados a los reyes, los ya conocidos del Tratado de Límites y de la corrupción de los ensendadistas, así como la reacción de Farinelli, que solicitó permiso para abandonar la corte en cuanto supo - por la reina- el desenlace, y la de Rávago, a quien el rey no se lo había dicho y no supo nada, según pensó Duras. Los dos se mantuvieron en sus puestos y Duras pudo continuar una provechosa relación con Rávago, que en adelante le informaría de las dificultades de Wall para tratar con el rey y de las acciones afortunadas contra los ingleses que se estaban produciendo en las costas de Honduras: "Le pere confesseur m'a fait dire que les espagnols avoient attagué les anglois à Rio Tinto et les en avoit chassésy) ${ }^{82}$, escribe Duras con regocijo.

El embajador supo también por Rávago que el tey no rompería nunca su relación de familia. Además, al fin murió el confesor de la reina y el puesto fue para la "cretura de Lefebvre», jesuita y profrancés. Rávago y Farinelli vuelven a hablar con los reyes, mientras, ya a la semana de los acontecimientos,

«M. de Huescar et $\mathrm{m}$. Wall etoient fort sombres et d'assez mauvaise humeur; ils ont trouvé le parti de $M$. de la Ensenada beaucoups plus considerable qu'ils ne $s^{3} y$ etoient attenduss ${ }^{83}$.

Y por si faltara poco, cuando empieza a tratar a los nuevos ministros, ve resucitar el espiritu de Ensenada en alguno.

Los grandes temores de Duras parecen desvanecidos. Al conocer y tratar a los nuevos ministros, se esfuerza en retratarlos ante Rouillé y Noailles como ensenadistas, sobre todo a Valdeparaíso y a Arriaga.

Cuando al fin, el 16 de agosto, Rouillé le comunica que su conducta ha sido aprobada por Versalles, puede tespirar satisfecho. Con todo, Noailles, que debe conocer las críticas contra el embajador que llegan ya al ministro - además ha muerto Saint Contest y el nuevo, Rouillé, no debe ser de su confianza-, le recomienda prudencia en lo que escriba. Para remontar la situación completamente, sólo le queda solicitar a Versalles que Luis XV envíe una carta a Fernando VI que selle la alianza y deshaga cualquier recelo que pueda quedar. El mismo envía un borrador y al fin, el 25 de agosto, Rouillé le comunica que

81 Choiseul a Ossum, 2 de junio de 1760, cit. en OzANAM, D., «La diplomacia de los primeros borbones (1714-1759)», Cuadernos de Investigación Histórica, 6 (1982), pp. 169-193, nota 37.

82 AAEP., T. 515, R., Madrid, 14 de agosto de 1754.

83 AAEP., T. 515, R., Madrid, 27 de julio de 1754 . Sobre el partido ensenadista, su fortaleza y sus esperanzas, OLAECHEA, R., "Politica edlesiástica...”. 
la carta ha sido aprobada. Sin embargo, Duras puede saber por su amigo Noailles que el rey no quería escribir esa carta y que, en realidad, va a aprovechar la que obligadamente tiene que enviar para comunicar un nuevo parto regio, para no aparentar interés en los asuntos internos de España ${ }^{84}$. Luis XV todavía esperará un mes para escribir, pero ya no setá una carta de cumplimiento sino una larga memoria sobre las hostilidades inglesas y austríacas contra la casa de Borbón.

El cambio de actitud regia fue paralelo a los acontecimientos de Madrid y Londres, que no evolucionaron como Duras creía a principios de agosto. Sus temores volvieron el 25 de agosto, al enterarse de que Jorge II había escrito una larga carta a Fernado VI quejándose de la política ofensiva española en América contra sus barcos. Es entonces, al conocer más noticias divulgadas por Londres, cuando se da cuenta de que no hay otra causa en la "desgracia» de Ensenada, y se explaya ante Noailles. Sabe el 1 de setiembre que Keene será condecorado y asegura que Wall y este embajador están tramando en secreto un tratado comercial favorable a Inglaterra. Wall ha suspendido todas las órdenes de acción en América, mientras Noailles comunica su temor de que los ingleses logren impedir la comunicación entre la Louisiana y el Canadá y apoderarse de Méjico, que es su objetivo secreto.

Ante esta nueva escalada de tensión, el 27 de setiembre Luis XV fecha una larga carta, durísima contra ingleses y austríacos:

«Les anglois ont eté de tout temps les ennemis constants et implacables de notre sang et de notre maison»(...) da cour de Londres veut envahir des tresors du nouveau monde et de procurer la monarchie universelle sur les mers».

Coincidiendo con los temores más arraigados de Duras y los ensenadistas, el rey descubre el verdadero motivo de las maniobras inglesas. Contra Viena, el argumento es diferente: una cuestión de dinastía:

(da cour de Vienne ne pardonnera jamais a la France d'avoir etablie Philippe V, votre auguste pere sur le thronne de l'Espagness 85.

Fernando VI contestó en noviembre con una carta que Ozanam ha juzgado anodina, pero que en realidad está en la linea definida por Carvajal y de la que Wall no se apartaría nunca. Demostraba que Duras no había conseguido nada, pero que tampoco Keene había ido más allá de la palabretía y el espectáculo. Con todo, provocó una gran decepción en Versalles y en la embajada francesa en Madrid. Fernando VI seguía igual a pesar de la evidente hostilidad inglesa; sólo hablaba de paz cuando se estaba preparando una guerra. "Con cuanto es-

84 AAEP., T. 512, Versalles, 22 de agosto de 1754.

85 AHN, Estado, leg. 6512. Copias de las dos cartas - la de Luis XV y la tespuesta de Fernando VI- y de una extensa memoria son enviadas por Wall a Masones en 27 de noviembre de 1754. Wall, a sabiendas del riesgo, prevenia a Masones; «de ninguin modo entre V.E. en particular contestación». Ver OZANAM, D., (LLa política exterior de España...), p. 681.

Hippania, LIX/1, núm. 201 (1999) 217-249 
tudio he procurado y solicito fomentar y establecer un tan saludable sistema (de paz)", decía el rey. Por si cabía alguna duda sobre lo poco que importaba el cambio ministerial, añadía: «trabajan tiempo ba mis ministros en la negociación de ajustar amigablemente las diferencias y puntos controvertidos con la Inglaterras ${ }^{86}$. Además, unos días antes se conocían en París las manifestaciones de Jorge II en el parlamento sobre «la amistad y la confianza» entre él y el rey de España, lo que aún afectó más al gobierno francés y al inquieto marqués de Duras que de nuevo comenzó a divulgar rumores de guerra. Masones se exasperó con él y acabó por denunciar su actitud ante el ministro Rouille, a sabiendas de que la relación de éste con Duras era mala desde el principio. El clima de julio se volvía a repetir, ahora sin un culpable. El embajador comunicaría por un intermediario al ministro la desastrosa política de Duras e, incluso, no dudaría en enviar a Wall esta información:

«Le he dicho (a Saint Séverin) la imprudencia con que (Duras) se muestra parcial del matqués de la Ensenada después de haber incurrido en la desgracia del rey, y enemigo con bravatas de los que le han sustituido, procediendo contra todos los principios de política y bajo un engaño manifiesto que es haber perdido en aquel ministro un amigo particular de la Francia, cuando seguramente no lo eza más que los actuales servidores de su amon ${ }^{87}$.

Un año después saldría Duras de Madrid. Parecía que nada había cambiado y así fue en efecto. La guerra que tanto se temía estalló y España mantuvo su neutralidad hasta que Wall fue relegado, en 1762, cuado ya gobernaba Carlos III, un rey que ni hizo la «feliz revolución» que pronosticaba el ensenadista $\mathrm{Pa}$ dre Isla ni devolvió a Ensenada al poder como pensaban sus hechuras en 1759 y temían sus muchos enemigos.

\section{ALGUNAS REFLEXIONES A MODO DE CONCLUSIÓN}

Muchos no se conformaron con tomar los acontecimientos de julio como un signo más de la mudanza de las glorias del mundo y, aunque pocos habían leído a Hobbes en España, lo que el filósofo había escrito en el Leviatán era pasto común de mentes despejadas.

«No hay para el hombre más forma razonable de guardarse de esta inseguridad mutua que la anticipación; esto es, dominar, por fuerza o astucia, a tantos hombres como pueda hasta el punto de no ver otro poder lo bastante grande como para ponerle en peligro.» ${ }^{88}$

86 Ozanam, D., «La política exterior de España...», p. 681. El sistema fernandino de paz se extiende de nuevo a sus ministros, con un antes extraño: «y contemplo a Vuestra Majestad instruido de lo principal, como yo to estaba antes por mis ministros".

87 AGS, Estado, leg. 4523. Masones a Wall, 18 de noviembre de 1754.

88 Hobres, T., Leviatán, Madrid, Ed. de C. Moy y A Escohotado, 1983, p. 222. Muchas de estas ideas provienen de mis conversaciones con el profesor José Martínez de Pisón, de quien

Hipania, LIX/1, núm. 201 (1999) 217-249 
Era el despotismo o, si se quiere, la Razón de Estado, como se denominaba en la España del XVIII al peligroso instrumento político y moral, del que Ensenada hacía "maestro consumado" en su empleo nada menos que al secretario de Estado del Papa, su amigo el cardenal Valenti ${ }^{89}$; Despotismo y Razón de Estado, que estaban ya a punto de iniciar un paradójico maridaje con monarquía absoluta no tiránica, reformista, paternalista y -en el colmo- ilustrada, y que, en España, eta - y seguiría siendo- cosa de ministros más que de reyes. Porque, en definitiva, fueton los déspotas ilustrados los que hicieron reyes ilustrados ...déspotas.

Ensenada había logrado llegar a la cima del poder, ser más que lo que era un ministro, gracias a la creación de una amplia red clientelar - idominar...a tantos hombres)--, pero había otro poder, incluso, todavía, otros poderes. Por eso un pasquín se atrevió a rozar la suma verdad:

\section{"los arcanos del rey no se indagan, se veneran."}

El altivo duque de Huéscar (luego de Alba) se había impuesto sobre un Fernando VI desorientado al que vestía y desnudaba todos los días como su Mayordomo, un rey que en su manifiesta incapacidad había dejado crecer el control de los asuntos políticos en manos de Carvajal y, sobre todo, de Ensenada. Era lo que el duque y los grandes querían frenar al comprobar que, desaparecido el secretario de Estado, el "pacifista» a ultranza y noble D. José de Carvajal y Lancáster, el marqués, con sus cuatro ministerios y su red de ensenadistas en todas las embajadas y en los puestos clave de la corte, tocaba ya todas las teclas de gobierno. No podían soportar la euforia y el éxito de Ensenada, ni estar seguros de que su sistema gradual de reformas no les alcanzara, incluyendo en él la amenaza de la Unica, una vez comprobado que el Catastro no era una utopía y se había podido realizar. Sin embargo, desviaron la atención sobre sus verdaderos temores y jugaron a la política internacional, el tema estrella en el Madtid cosmopolita de después de Aquisgrán y, políticamente, el último arcano regio. Por eso los historiadores, desde Rodriguez Villa, han culpado a la situación internacional, como hace Dominguez Ortiz: "más preocupado por las reformas interiores, la caida de Ensenada estuvo estrechamente ligada a cuestiones de politica exteriom. Y Lynch, en la misma línea, piensa que "un gobierno dedicado a la promoción del poder nacional fue víctima de un escandaloso ejercicio de desestabilización protagonizado por un interés extranjerons ${ }^{90}$.

No reparaba Ensenada en que un secretario de Guerra y Marina no declara la guerra ni tompe por su cuenta la neutralidad de la monarquía, ni mantiene

es una obra absolutamente recomendable: Justicia y orden politico en Hume, Madrid, Centro de Estudios Constitucionales, 1992. El interés para los historiadores sobrepasa el que se desprende del titulo.

8) AHN, Estado, Ensenada a Valenti, 14 de julio de 1750.

9 Dominguez Ortiz, A., Sociedad y Estado en el sigho XVIII español, Barcelona, 1976, p. 287. LYNCH, J, E/ Siglo XVIII, Barcelona, 1991, p. 175.

Hìpunia, LIX/1, núm. 201 (1999) 217-249 
relaciones exteriores que son sólo asunto de familia, de casa y de sangre. La actuación de Ensenada en la cuestión de Honduras y la costa de los Mosquitos y, presuntamente, su relación con Carlos de Nápoles, sobre todo en asuntos familiates como eran por ejemplo, el Tratado de Aranjuez — no hay más que ver las cartas cruzadas entre Fernando y Carlos-, interferia en la autoridad regia, por supuesto absoluta. Era un crimen de estado, como dice Duras que lo calificó la reina, un acto autónomo del Estado que suplantaba al rey. En efecto, había algo arriba que podía hacer realidad aquello que Ensenada le dijo a su amigo Valenti, al que más se confió: «Yo, en un accidente, seré nadas" $"$.

El marqués supo al fin (por donde iba a estallar la tormentay - son palabras suyas-, el accidente que esperaba desde la muerte de Carvajal: coor donde menos podia pensan, dijo luego, al conocer que al tey le habían presentado sus planes ofensivos, prebélicos, contra los ingleses como cargo principal Sin embargo, cuando le arrestaban, de lo que se acordó fue de su origen humilde - «je sais a queje szis né, et je ne l'ai jamais pertu de ruen, dice Duras que dijo al despedirse $\%$ - y sus amigos culparon a los grandes de España, con Huéscar a la cabeza, aunque reconocieron que la nobleza use compadeció en ver tan mudada su fortunas ${ }^{93}$. Se referían sólo a una parte de ha nobleza, a la que estaba ya habituada a no tocar poder desde el cambio de dinastía, no a la de las grandes casas como la de Alba, que vieron llegar demasiado lejos las reformas y su motor: el Estado administrador, el personal a su servicio. No sólo Ensenada era un hidalguillo plebeyo, sino que lo era también buena parte de su vasta clientela, empezando por Ordeñana ${ }^{\text {s4 }}$, un improbable candidato a suceder a Carvajal, y terminando por los Orcasitas, Francia, Pérez Delgado, etc., que ocupaban puestos claves en la administración de la maquinaria estatal ${ }^{25}$.

91 AGS, Estado, leg. 2850. Ensenada a Valenti, 5 de enero de 1751.

92 AAEP., T. 515, R, Madrid, 27 de juilo de 1754.

93 BN, mss., 3790, Colección de varios documentos, ff. 5-63.

94 La extraordinaria biblioteca de Ordeñana, de cuyo estudio se ocupa Cristina González Caizán, doctoranda de la Universidad de La Rioja, mostrará hasta donde llegaba el cosmopolitismo de gente aprentemente gris y desconocida en la historiografia, en un intento más de rescatar la ilustración precarolina y empezar a matizar los brillos parisinos y su irradiación por contagio. V. mi articulo «El artificio temporal y su responsabilidad en la reconstrucción histórica: la tópica petiodización del XVIII español», Moutement et discontinuité, U. de Saint Etienne, 1995.

${ }_{95}$ No se puede teorizar sobre el Estado y la monarquía en el XVIII sin tener en cuenta la composición social sobre la que se asienta. Olvidar el papel de la nobleza y su sitio en los (uestadoss) fomenta interpretaciones presentistas, excesivamente tributarias de la teoria juridica que frecuentemente se ampara en elementos posteriormente desarrollados en la práctica. Un ejemplo muy reciente de esta oleada de aparentes novedades teóricas se puede ver en P. Monod., para quien «da idea de estado se relacionará no con una teoria específica, sino con una concepción orgánica de la organización política, que entendía la política como un cuerpo colectivo que englobaba los intereses de todos sus miembros. El gobierno era la cabeza, la expresión última de la soberanía sobre ese cuerpow. MONOD, P., «Estado, nación y monarquia en el siglo XVIII: Visión comparativa», en Las monarquias del Antiguo Régimen: zmonarquías compuestas?, Madrid, Cursos de verano de El Escorial, 1996, pp. 11-30. Una reflexión sobre los «estados» y la noción de Estado en la Francia de Luis XIV (que nos interesa por su influencia en el gobierno de Ensenada), puede verse en SCHULzE, H., Estado y na*

Hispania, LIX/1, núm. 201 (199) 217-249 
El Estado administrador chocaba contra la domus regia y su prolongación: «la corte representó siempre el campo de acción primario e inmediato, mientras el país sólo constituía uno mediato y secundarios " ${ }^{*}$. Ensenada, el servidor del Estado reformador y de ese "país mediato y secundario» - y todavía difuso-, crispaba a Huéscar el mayordomo de la Casa Real, servidor de una (nnación» que, como grande entre los grandes, entendía como prolongación de los dominios domésticos de la Monarquía sólo "servidos» por el personal estatal, de los que él, el más cercano al rey, era un apéndice naturalmente implicado en su gobierno (no en su servicio): un gobierno ad majorem gloria dei. Por eso, el primer cargo con que se adornó Huéscar en su interinato tras la muerte de Carvajal y mientras se esperaba la llegada del ya Secretario de Estado su amigo Wall, fue el de "decano» del Consejo de Estado, la vieja maquinaria de ratificación de honores de la polisionodia hispánica que Ensenada habia oscurecido del todo hasta hacer exclamar al embajador francés:

"place sans fonctions, puis qu'il n'existe point de Conseils» ${ }^{27}$.

Meses antes de la crisis, cuando Huéscar empezó a maniobrar públicamente en la corte contra el hidalguillo medrado y sus bechuras, el astuto Noailles hizo una reflexión sobre la situación que interpretó certeramente en clave de oposición entre "despotismo de los secretarios de estado" y ugrandes relegados del gobierno efectivon:

L'orgueuil des grands souffre de se voir subordonné et comme soumis a des personnes dont la naissance est si inferieure a la leur, et qu'il desireront fort voir revenir l'ancien gouvernement tel qu'ils etoit sous Charles V et Philippe II et leurs successeurss ${ }^{98}$.

Hasta tal punto llevaba razón Noailles se puede comprobar viendo como Huéscar llegó a idear una junta de grandes tras la derrota del ensenadismo. Los rumores que habían llegado al embajador francés hablaban de un junta presidida por Huéscar en la que estarían el conde de Montijo, el de Montellano, mayordomo mayor del Infante Cardenal, el duque de Alburquerque, el duque de Béjar y el de Salas. También estarian Wall y Eslava. El proyecto, si lo hubo, no pasó del rumor, pero dio pie al embajador a reflexionar sobre lo difícil que iba a ser ya que se lograra conjuntar a la gran nobleza en tareas de gobierno efectivo: Salas, «un bomme superieun», y Montijo eran, sin embargo, muy amigos de Ensenada y no podían sufrir a Huéscar; también estaba con ellos Eslava kel viejo loco ensenadista», «verd et d'une grande fermeté»; además, «M. de Montellano est un

\footnotetext{
ción en Europa, Barcelona, 1997, por ej. en pp. 50 y ss. Sobre la función de la corte y los órganos administrativos, sigue siendo muy interesante volver a Elías, N., La sociedad cortesana, Madrid, 1993 (reimpresión de la edic. de 1982, $1^{a}$. edic. en 1969).

96 ELfAS, N., La sociedad cortesana..., p. 61.

97 AAEP., T. 515, Madrid, SC, Aranjuez, 22 de mayo de 1754.

98 AAEP., T. 512, Noailles a Duras, Versalles, 4 de mayo de 1754.

Ihispania, LIX/1, nün. 201 (1999) 217-249
} 
imbecile, $M$. de Alburquerque est un bonnete bomme sans vues et sans lumieres, $M$. de Bejar bonnete bomme et paurre bomme, fot pieux, et assez disposé a une aliance etroite avec la Francen. Son expresiones que recuerdan las que Orry y Amelot lanzaban contra los grandes en el primer gobierno de Felipe V, cuando intentaban implantar las reformas para una nueva administración, evidentemente a la francesa, que tanto deseó el desgraciado Macanaz "'.

La Corona y los grandes, los viejos mecanismos feudales y la tradicional constitución del Reino volvian a chocar con algo nuevo, mal definido todavía, un despotismo ministerial que luego se llamaría ilustrado, cuya función principal era servir y servirse del Estado para reforzatlo. El borroso papel del rey y de la corte en esta difusa novedad que cada vez se impone más en las relaciones políticas —ubasta el más absoluto de los monarcas actuaba sobre su país a través de la mediación de bombres que tivían en la corte» ( $N$. Elías) - y la necesidad evidente de administrar, es decir, de desarrollar órganos de poder que necesariamente crecerían, más o menos —esa es la cuestión-, al margen del escenario cortesano hasta entonces «experiencia total» y «unico espacio político" posible, es lo que iba a seguir produciendo efectos «extraños» a lo largo del siglo en la carreta de los ministros del despotismo y, por ende, en las soluciones estatalizadoras que llamamos reformistas ${ }^{160}$. Por otra parte, la creciente complejidad de las relaciones internacionales en un siglo que descubrió la guerra puramente comercial, tecnificada, y la diplomacia como alta escuela de política de Estado, se configuró como elemento de autonomía necesariamente abocado a impulsar las reformas en todas las cortes. Las ideas políticas básicas circularon por las naciones de la Europa de los déspotas - desde luego, por España - con menos dificultades de lo que se piensa; quizás el primer espacio político de unidad europea habría que buscarlo en la Europa de los déspotas y ...de las activas embajadas dieciochescas.

99 V. Baudrillart, A., Pbilippe $V$ et la Cour de France, Paris, 1900, y mi trabajo El proyecto reformista.. Macanaz es uno de los hombres más interesantes del siglo XVIII español al que hay que conocer después, en su exilio. Es urgente completar los textos de C. Martín Gaite y conocer al Macanaz de Breda y de la prisión, en lo que tanto tuvo que ver Ensenada. Su Testamento es un texto extraordinario, v. BN, mss, 3790, ff. 67-113.

100 Véase FERnÁNDEZ AlbadAlEjo, P. «La monarquía», en Actas del Congreso Internacional "Carlos III y la Ilustracion, t. I., Madrid, 1989. pp. 1-90. Ademas de las reflexiones generales, es de gran interés, en relación con la contradicción que hemos señalado, el papel que para el autor desempeña Ensenada. La linea de actuación de Ensenada «suponía aceptar como principio la definitiva postergación de la monarquía jurisdiccionalistas. Y sobte la gradación con que Ensenada aplicó sus teformas, y la oposición que iban a encontrar «...de por medio estaba la presencia - y vigencia - no menos indiscutible, y con todo su pasado detrás, del orden tradicional de la monarquíar. pp. 48-49. Veáse también un interesante estado de la cuestión en la introducción en GUIMERA, A. (ed.), El reformismo borbónico, Madrid, 1996.

HLipania, LIX/1, núm. 2 (11 (1999) 217-249) 